أماكن الاستشفاء من خلال الطرز المعمارية المصورة في فسيفساء مدبا

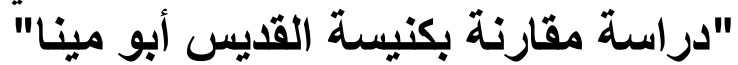

\title{
PlacesHospitalizationthroughArchitectural Stylesdepicted in
} theMadabaMosaic

\section{"Compared tothe Church ofSt.Abu MenaStudy" \\ د/ سماح محمد الصاوى}

تعد خريطة مادبا(') أمن أشهر وأميز الأعمال الفسيفسائية(صورة رقم () الموجودة في

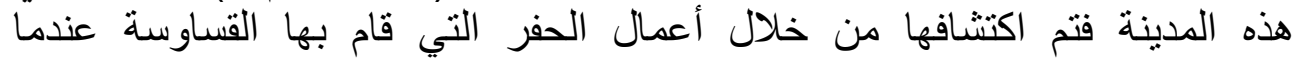

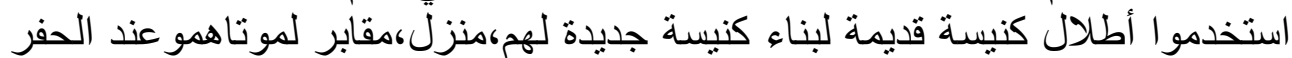

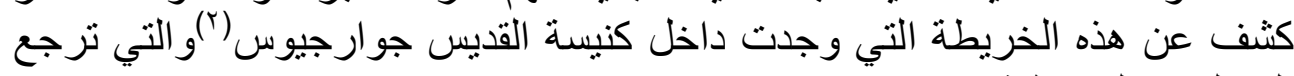
إلى الفترة البيزنطية.

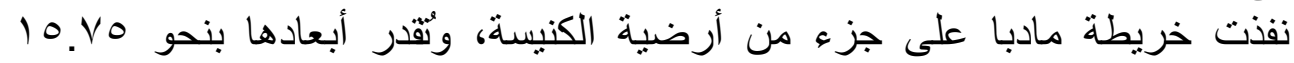

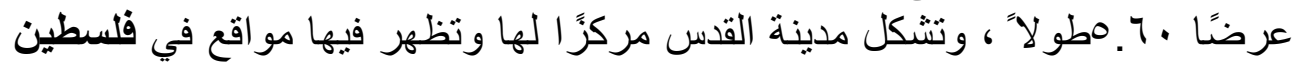

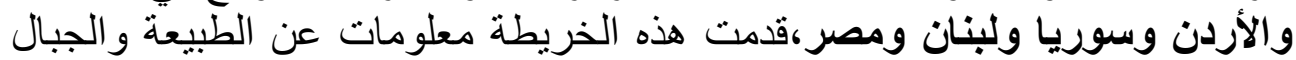

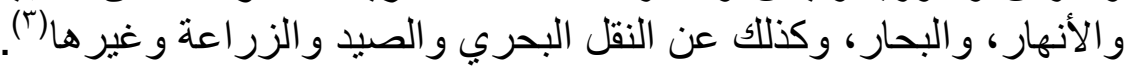

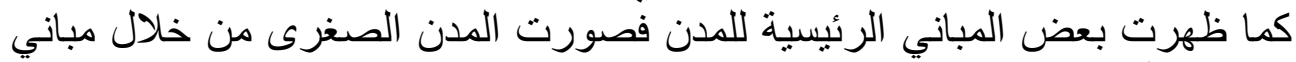

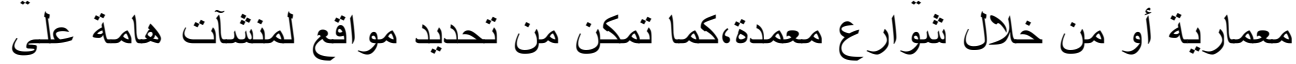

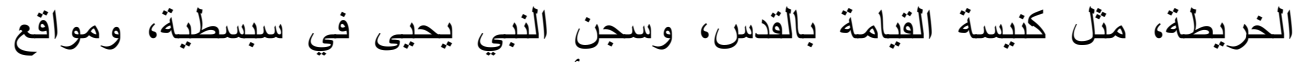
رومانية في قيسارية وبئر يعقوب في نابلس والأماكن الاستشفائية و غير ها من المباني الأخرى.

•أستاذ مساعد بقسم الآثار اليوناتية الرومانية بكلية الآداب جامعة الاسكندرية.

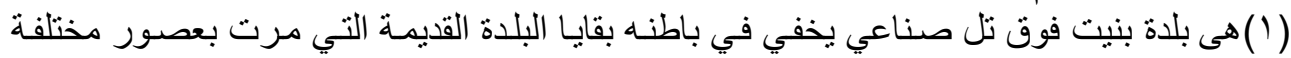

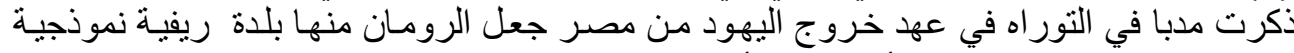

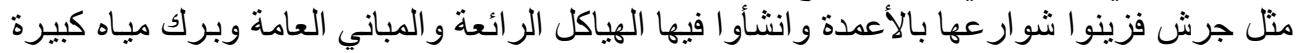

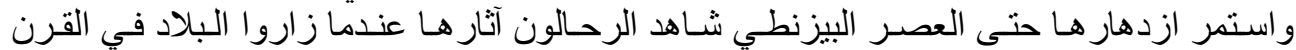

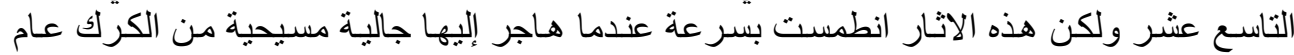

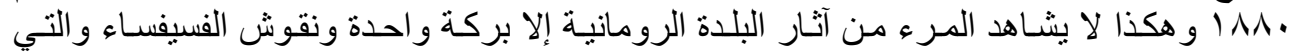

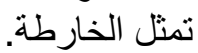

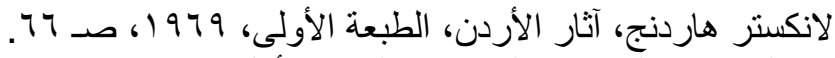

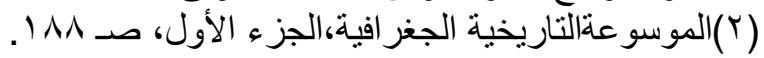

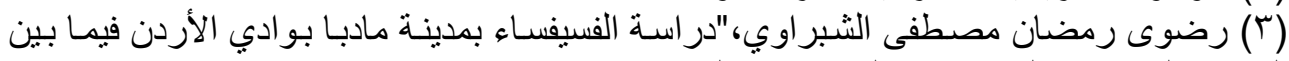

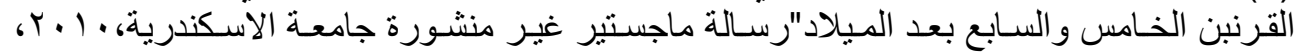
صـ 10. 
لم يتعرض الباحثين لار اسة هذا الفسيفساء ككل،ولكن كان الاهتمام الأكثر بخريطة

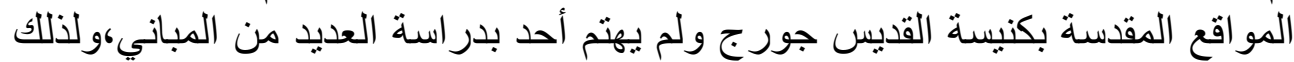

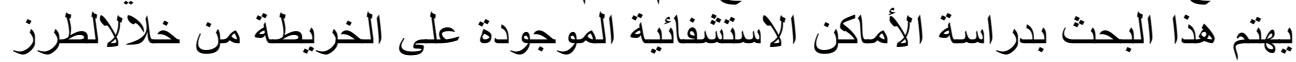

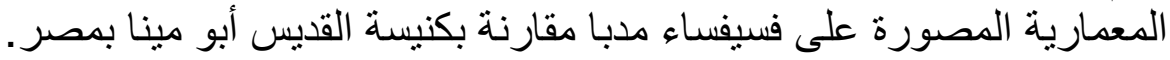

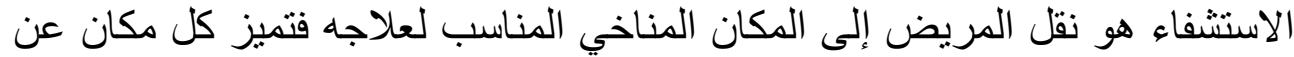

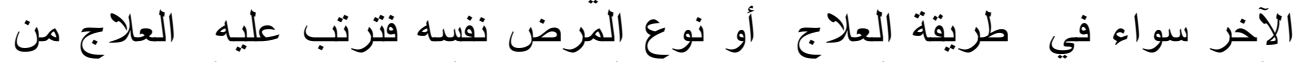

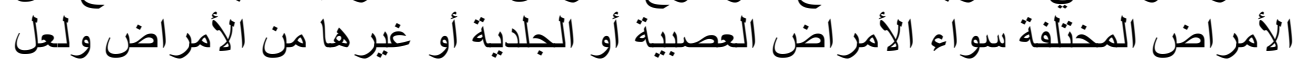

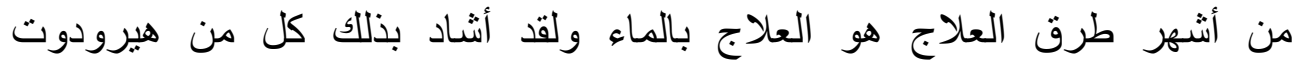

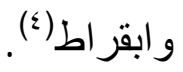

العلاج بالمياه هو مصطلح شائع لمجموعة من العلاجات سواء عن طريق الون الاستحمام

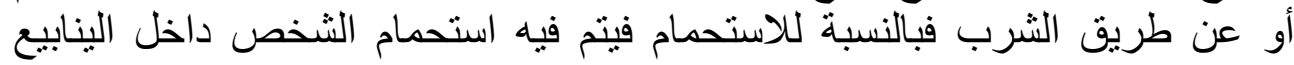
العلاجية الطبية ذات درجات الحرارة المختلفة بالإضافة إلى استخدام المياه المعدنية أو عن طريق مياه البحر.أما بالنسبة لشرب الثراب الماء فيكون إما عن طريق مياه الإن الينابيع العذبة أو عن طريق الآبار. حدد الفنان وصور على فسيفساء خريطة مدبا خمسأماكن استشفائية سواء نفاء نفذها في

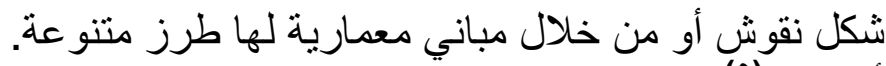

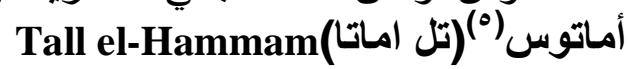
يقع بالقرب من الحافة الشمالية العلوية فوق نهر الأردن( في الجنوب الغربي لبيسان)

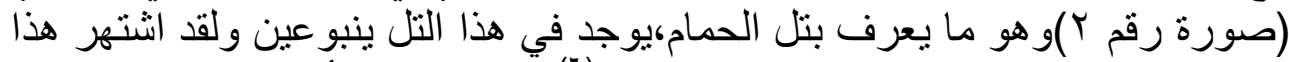

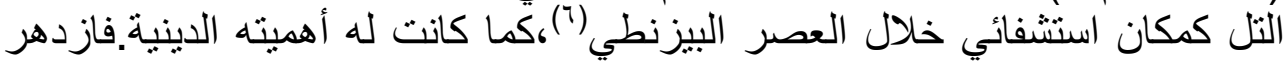

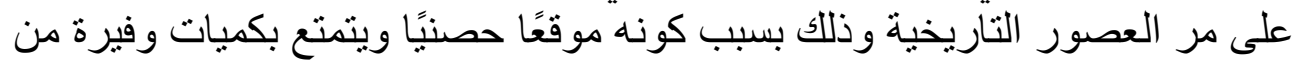

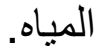
يعتبر وجود مثل ذلك التل على الخريطة بمثابة مقياسا لأهميتها فصورت هذه المدينة

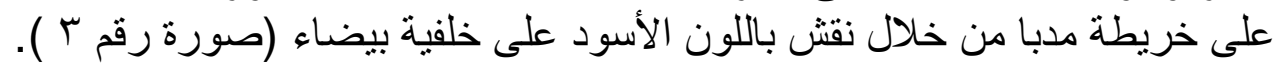

(4) http://www.christusrex.org/www1/ofm/mad/discussion/020discuss.html.

(0) أماتوس هو ملك اسطوري صديق للملك كينورس له قبرص الأسطوري اشتهرت عبادة أفروديت في اماتوس كما اشتهرت في قبرص لمات Aupert, p., 1997, “Amathus during the first Iron Age”, BASOR, vol308,pp19:23

(T) أجريت حفائر لموسمين وتمت هذه الحفائر تحت اشر افs Dr. Steven Collins 
Ain sultan مقام القديس اليشع)

وهو المعروف باسم عين سلطان (^)وهو من أشنر ينابيع الأردن يقع في جرش،صور

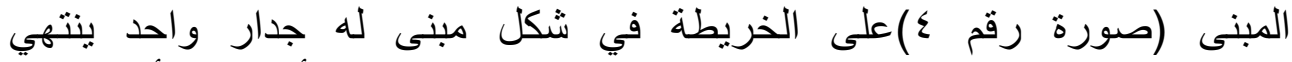

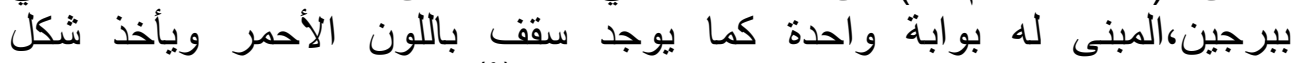

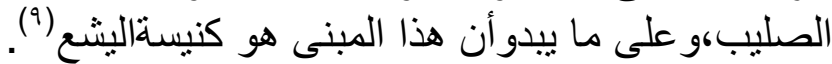

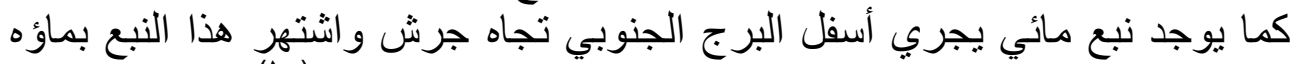

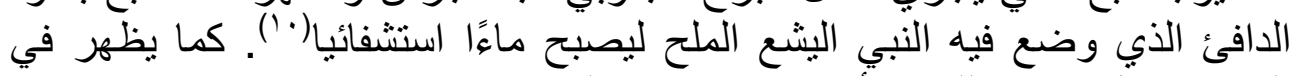

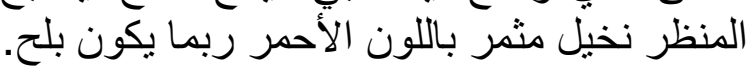

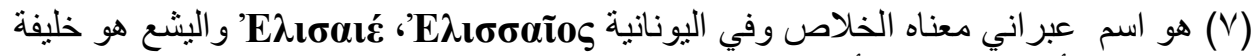

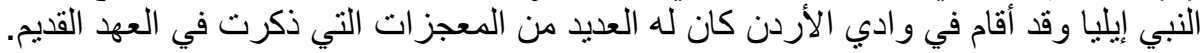

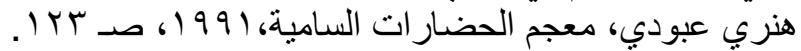

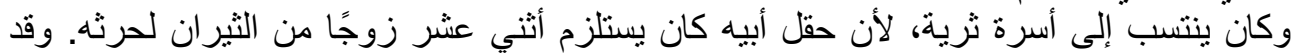

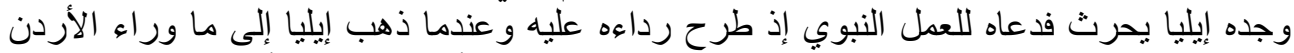

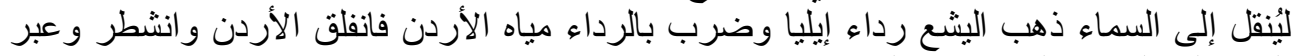
اليشع إلى الجانب الغربي من النهر النهر. http://st-takla.org/Full-Free-Coptic-Books/FreeCopticBooks-002-Holy-Arabic-BibleDictionary/01_A/A_377.html

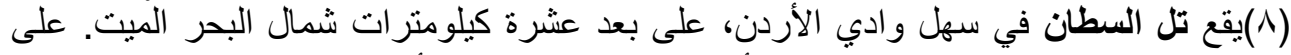

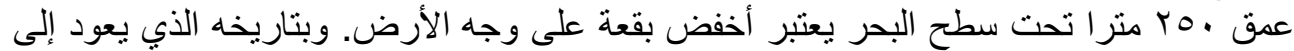

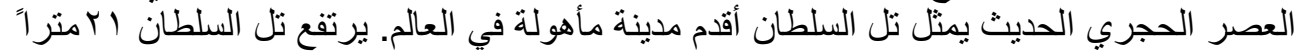

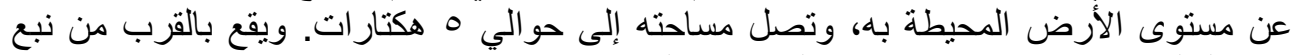

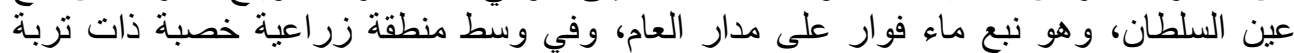

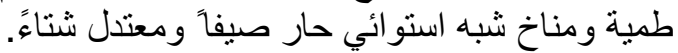

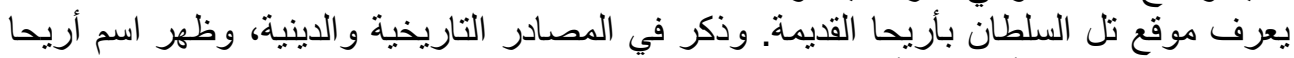

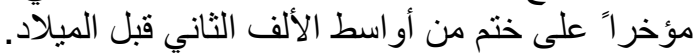

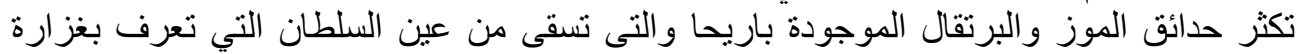

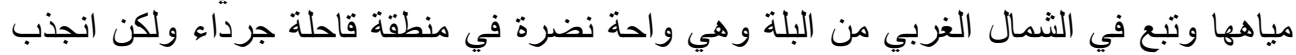

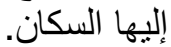

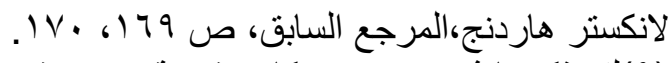
(9)قد ذكر ها ثيودو سيوس وكانت قريبة من جرش وكذلك من نبع اليشع

Tsafrir, Y., 1986, "The Maps used by Theodosius. On the Piligrim Maps of the Holy Land and Jerusalem in the Sixth Century C.E”, DOP, P. 137.

(10)Mathews, S., 1898, “In Elijah’s Country”, BW,Vol.12, No.3,P.163. 


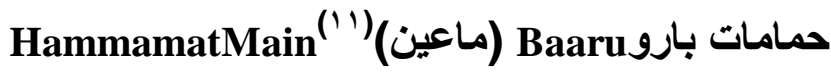

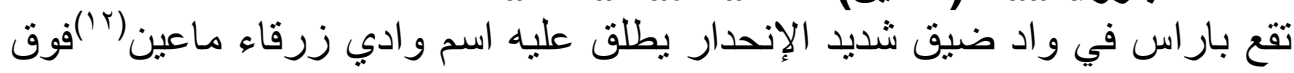

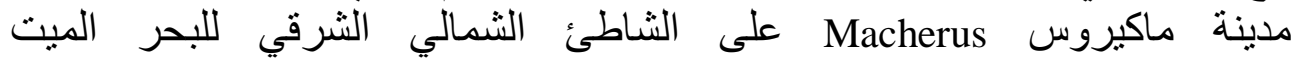

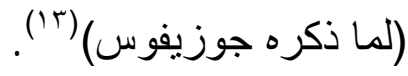

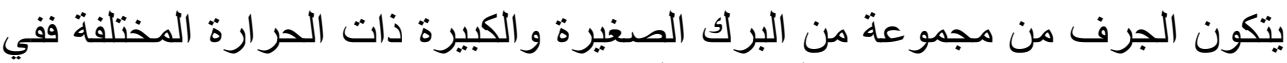

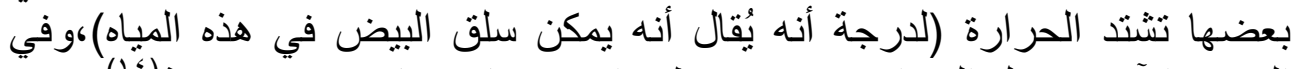

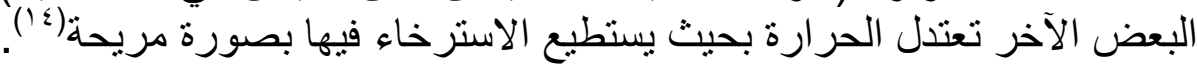

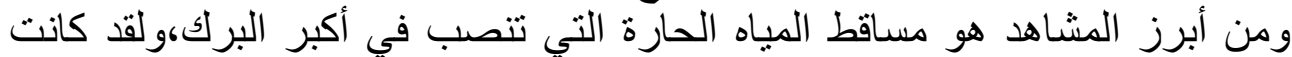

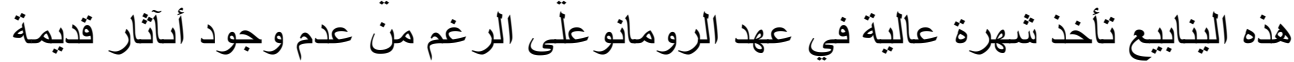

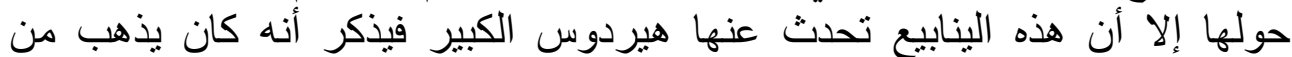

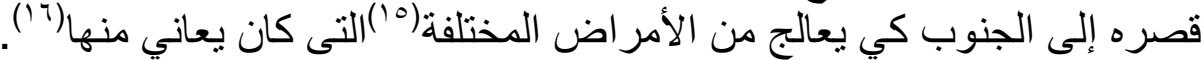

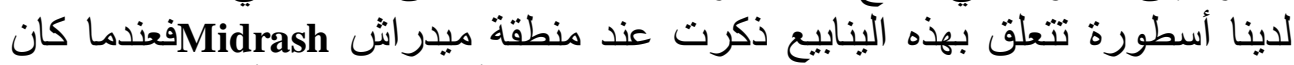

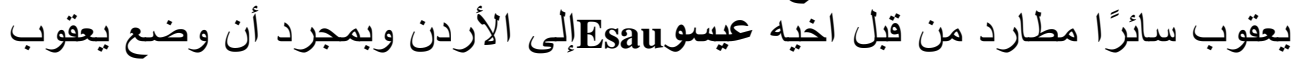

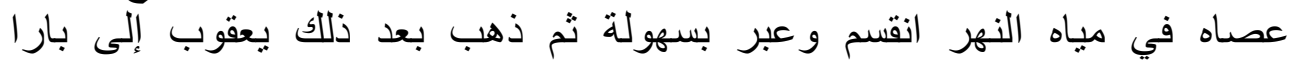

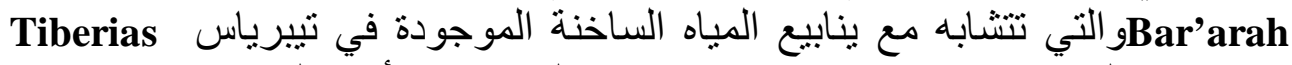

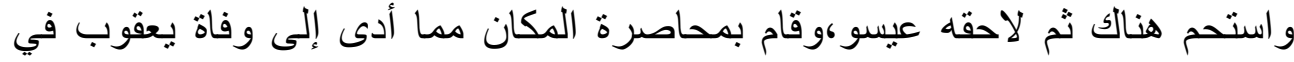
ذذه الينابيع الساخنة،ولم يفتح لله الرب الطاب الطريق ليهرب في الينابيع الباردة حيث ذهب هذه (iv) وبفضل هذه المعجزات أشنار النبي (السيد المسيح) للى يعقوب قائلاً "عندما مررت خلال تلك الينابيع سأكون معك وعندما تسير في النار لا تحترق ولا تنوه هج النار

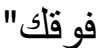

تتميز بار اس بوجود نباتات بها تحمل نفس الاسم و الذي اشتق منه نفس اسم المدينة

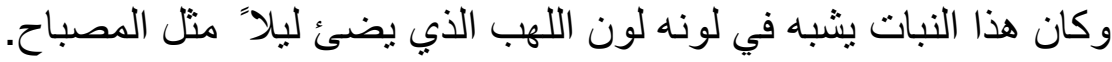

$$
\text { V) Vـ (1') }
$$

(12) Donner ,H.,1984, "Transjordan and Egypt on the Mosaic Map of Madaba”, ADAJ, Vol 28, P.249

(13) Josephus, Jewish War I, 657 - 659; Josephus, Jewish Antiquities, XVII, 169 - 176

(14) Josephus, Jewish War, VII, 177 - 184, 3

(15) Josephus, Jewish Antiquities, XVII, 166 - 170, 5; Josephus, Jewish War, I, 652 - 656

(16)Weber, T., "Thermal Spring, Medical Supply and Healing Cults in Roman-Byzantine Jordan”, SHAJ, Vol6, P333

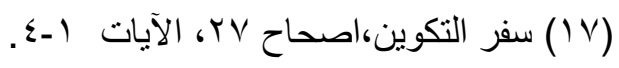


كما يلاحظ وجود كهف (محاط بصخور) يبرز من صخرة تربط بين تلين ناتثئين

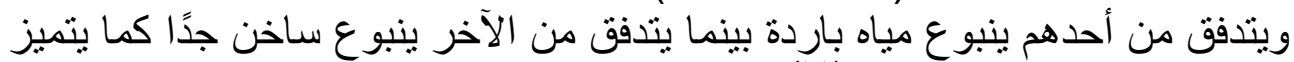

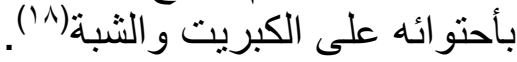

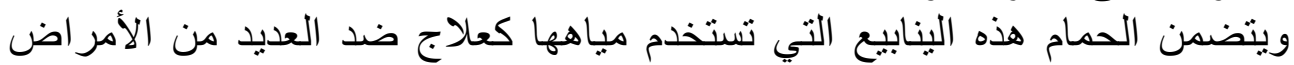

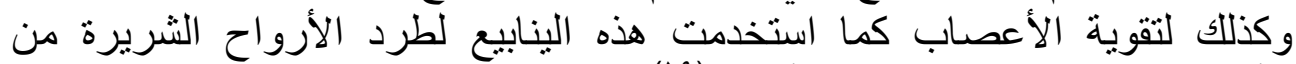

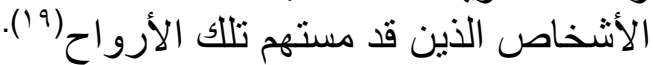

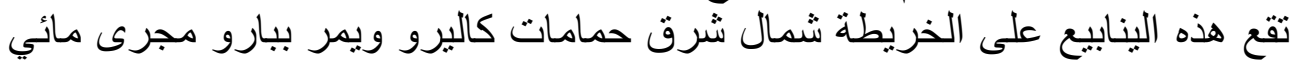

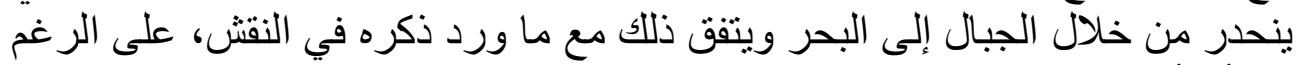

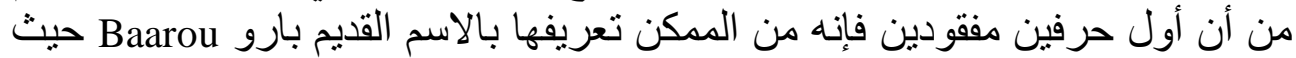

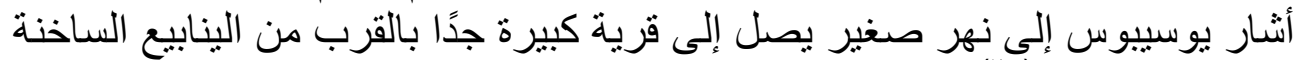

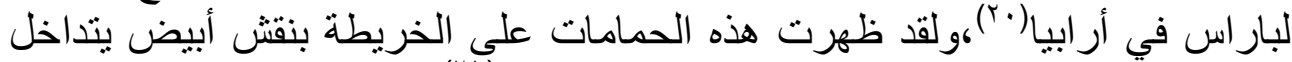

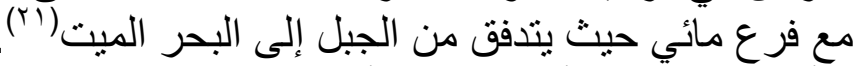

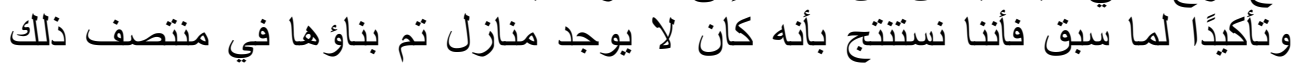

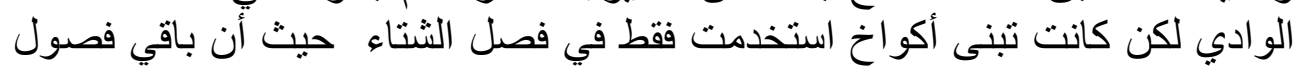

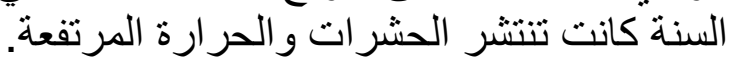

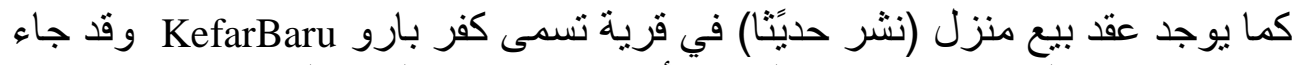

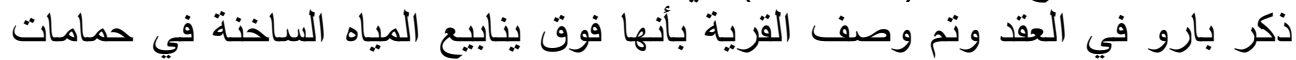
ماعين والتي تبعد في كم كم ون ماكريوس.

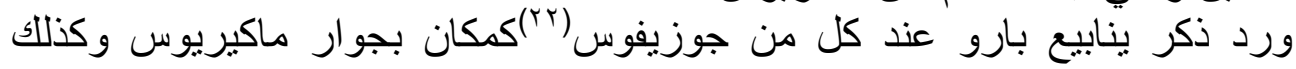

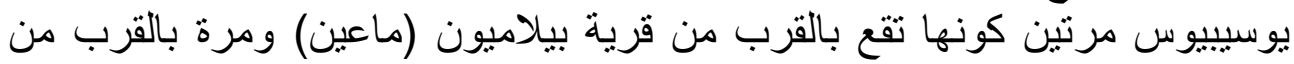

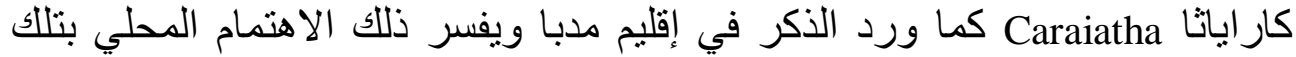

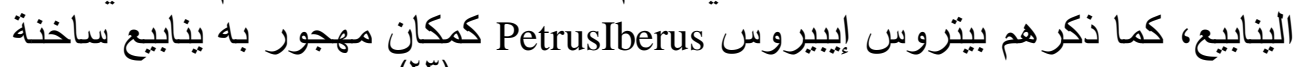

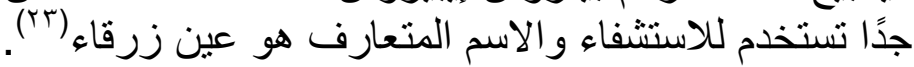

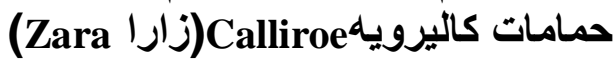

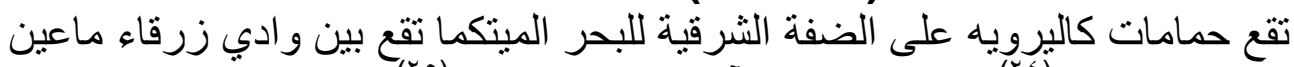

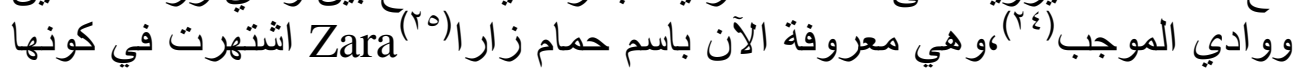

(18) Josephus, Jewish War, VII, 177 - 184, 3; 18Josephus, Jewish War, VII,180 - 189.

(19)Pliny, Hist Nat, XXVIII, 23.

(20)Eusebius, Onomasticon, 44: 22; 112: 117.

(21) Pliny, Nat Hist, V, 16; Ptolemy, Geogr, V, 16.

(22) Josephus, Jewish Antiquities, XVII, 166 - 170, 5.

(23) Clamer, Christa, The Hot Springs of Kallirhoe and Baarou, 2002, p.4

(24) Donner, Op.cit,P39-40

(25)Piccirillp, Michele, 1997: 199 


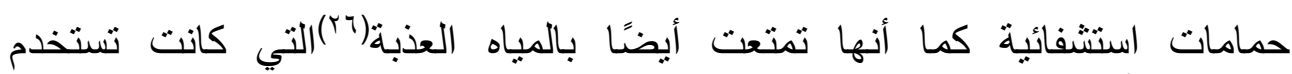

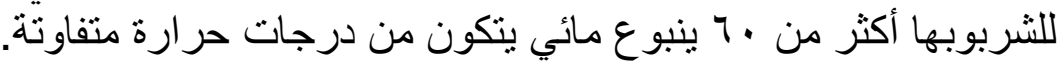

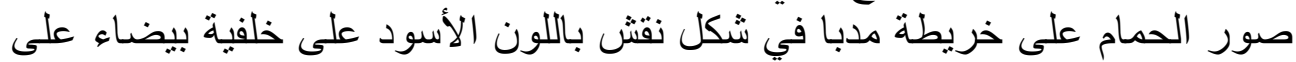

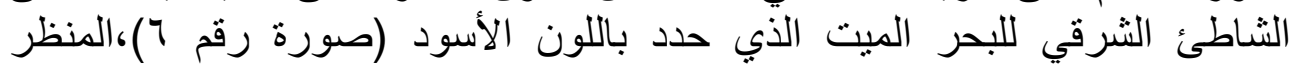

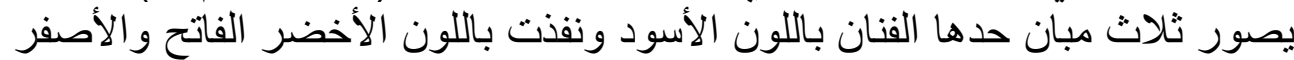

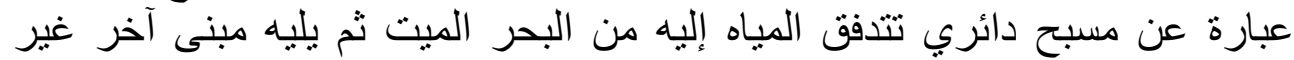

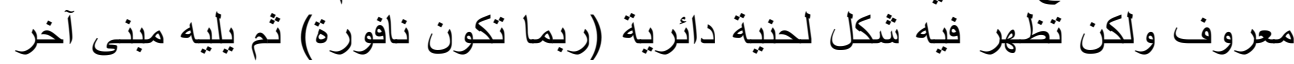

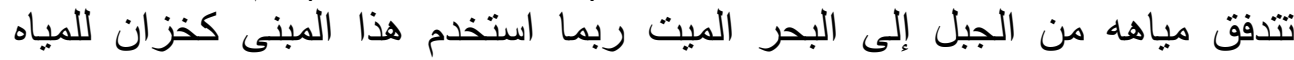

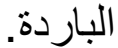

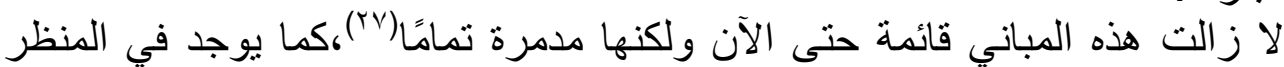

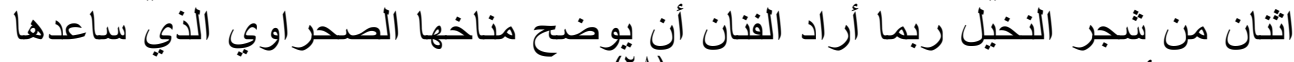

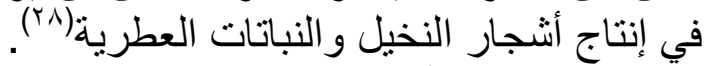

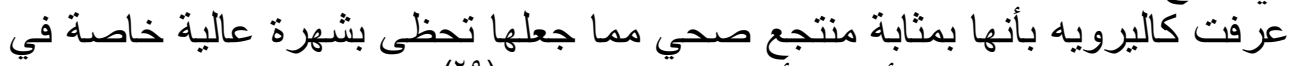

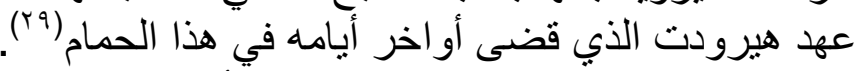

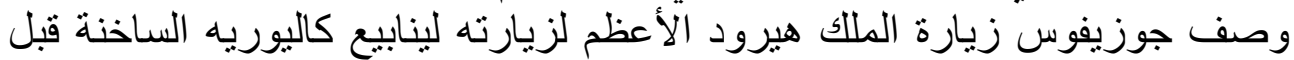

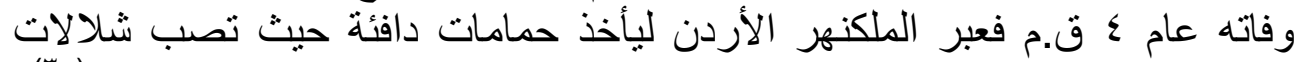

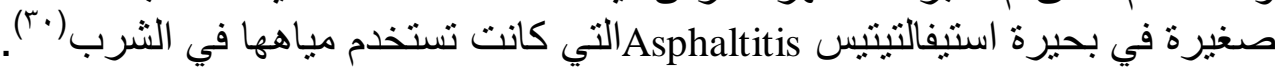

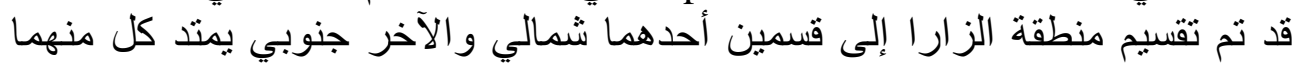

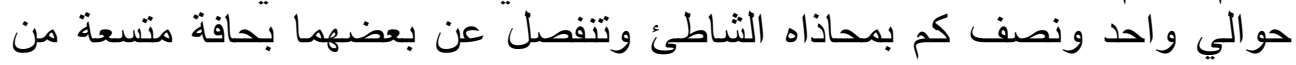

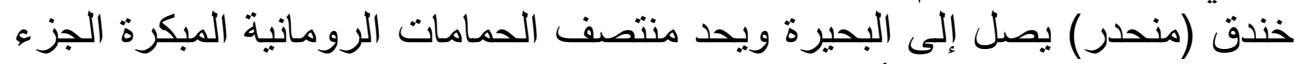

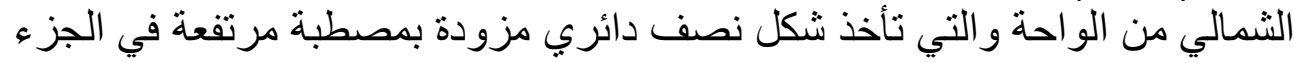

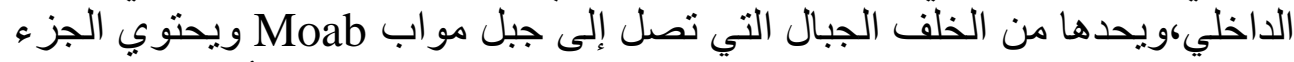

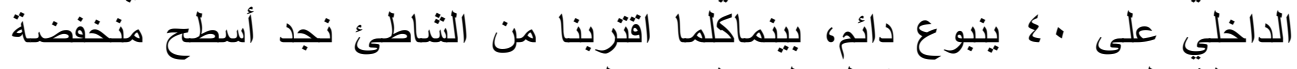

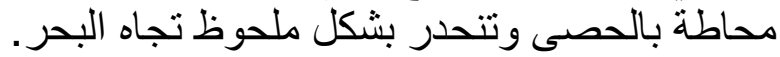

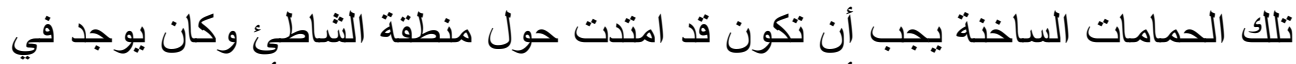
الجزء الغربي ميناء صغير أو مرسى وصات فون فيات مزودة بصفوف أعمدة يؤدي إليها

(26)Josephus, Jewish War I, 657 - 659; Antiquities, XVII, 169 - 176

(27)Donner, 1992, Op.cit., pp.39:40

(28)Clamer, 1999, Op.cit., P. 223

(29)Donner, H., 1963, "Kallirrhoe, das Sanatorium Herdes, des Groben, “ZDPV, Vol79, PP59:89.

-Clamer,C.,1999,'The Hot Spring of Kallirrhoe and Baarou”,Michele Piccirillo,Eugenio Alliata(Edit.,),in :The Madaba Map Centenary 1897-1997:Traviling through the Byzantine Proceeding of Umayyed Period the International Conference Held in Amman 7-9 April 1997, Jerusalem, P.221

(30) Josephus, Jewish Antiquities, XVII, $170-174$ 
درجات متسعة تمتد من الميناء وتصل حتى مباني الحمامات الدافئة ومباني أخرى تصل إلى البحر.

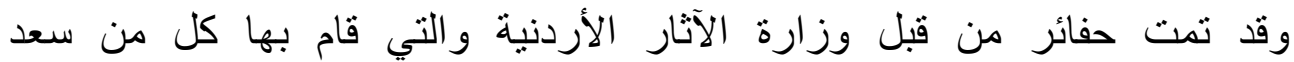

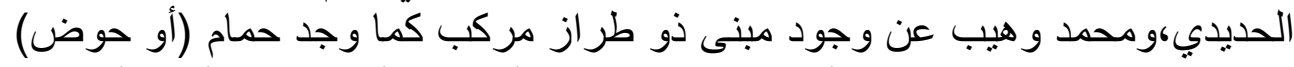

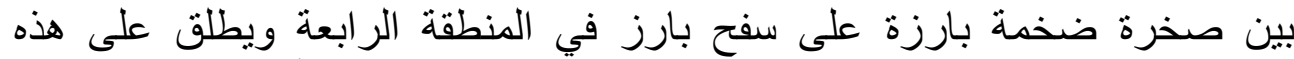

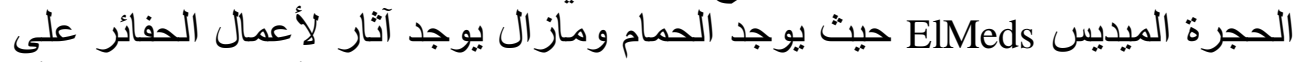

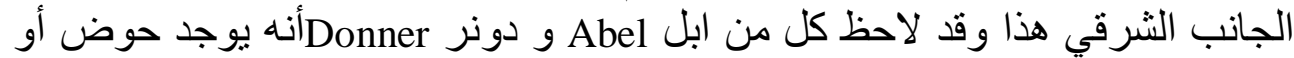

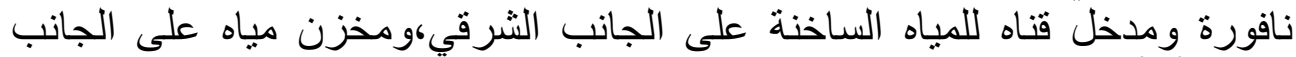

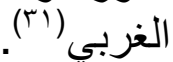
تعتبر كاليرويه حلقة الوصل بين مبنى هيرود في جرش وقصر ماكيريوس Machaerus الساخنة،ومر اكز التسلية بالقرب من شاطئ البحر حيث تندفق بنابيع المياه الساخنة في

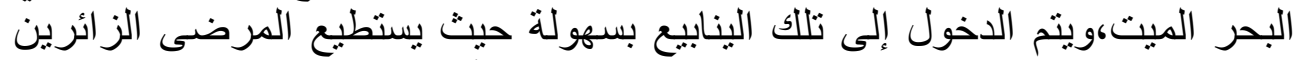

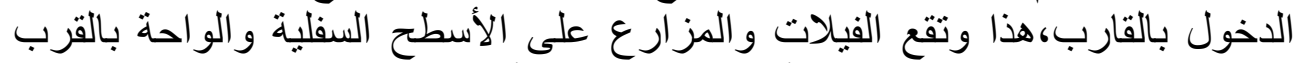

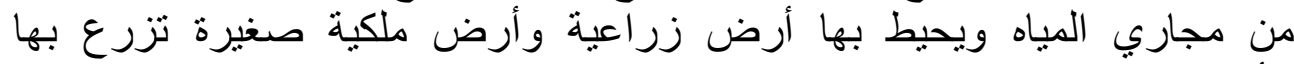

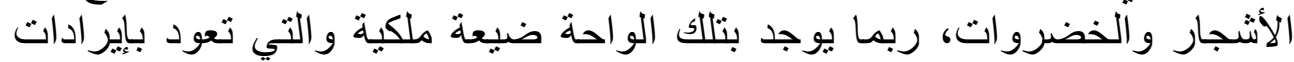

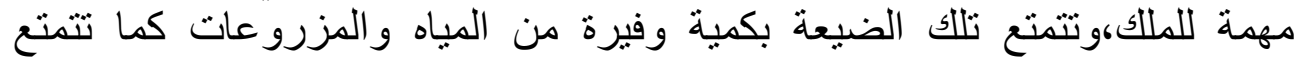

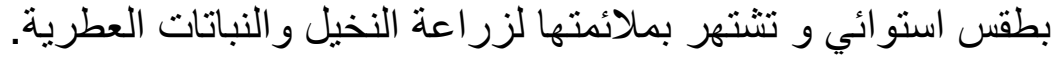

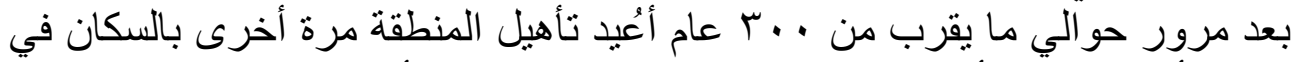

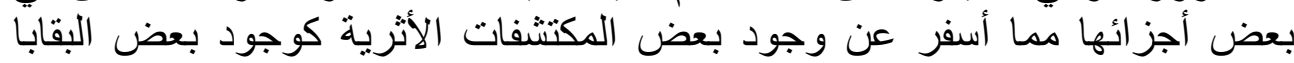

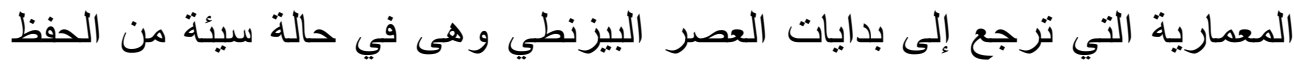

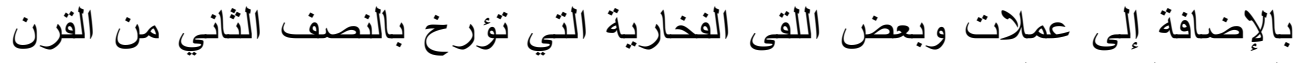

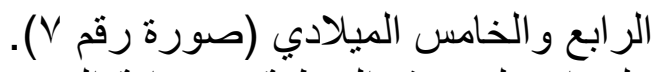

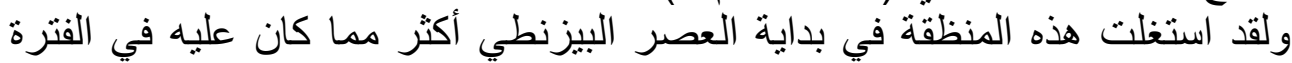

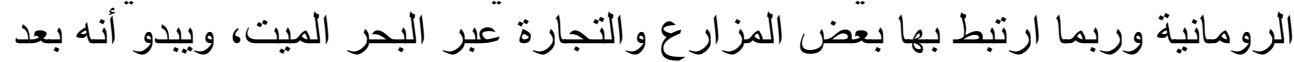

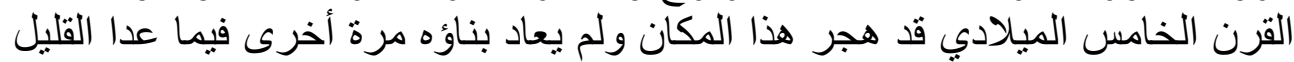

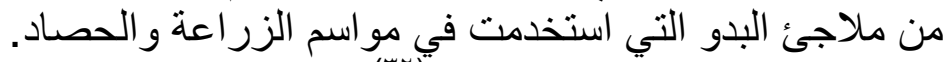

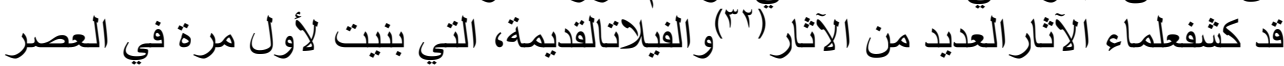

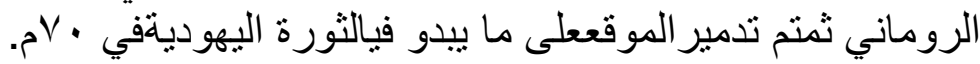

(31) H. Donner, The Mosaic Map of Madaba, Kok Pharos, Kampen, 1992, p.19 - 25

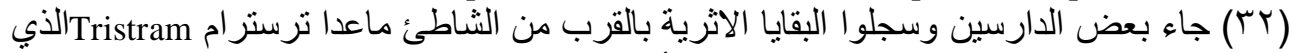

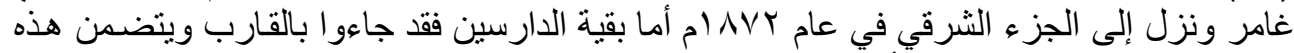

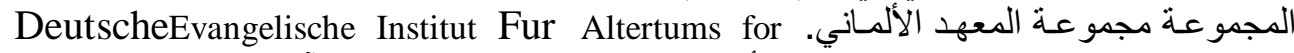

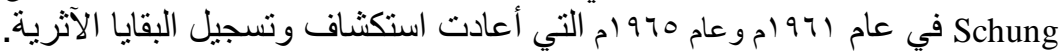




\section{ميوماس(بّ) (عين سارة)}

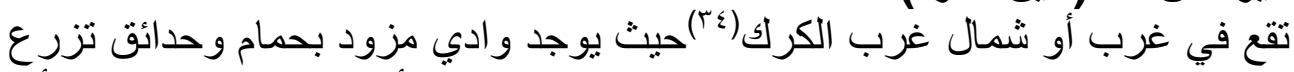

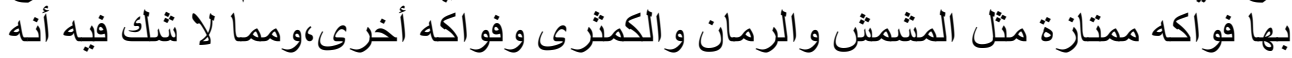

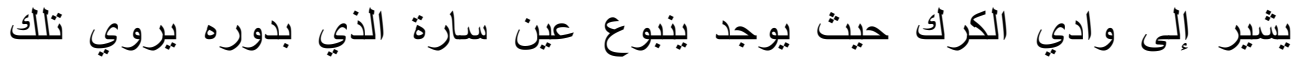

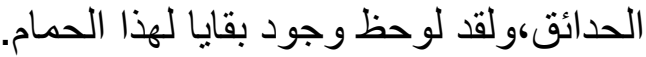

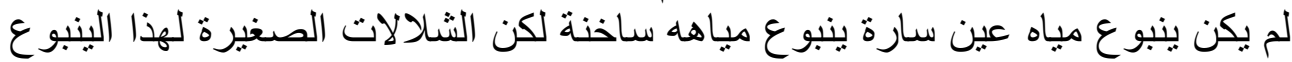

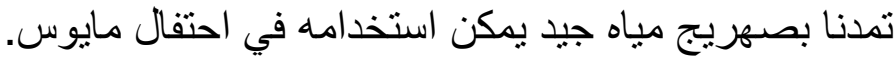

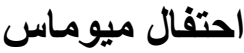
عرفت بداية نشأة هذا الاحتفال في غزة حيث يوجد مئ ميناء أطلق عليه في الآرامية

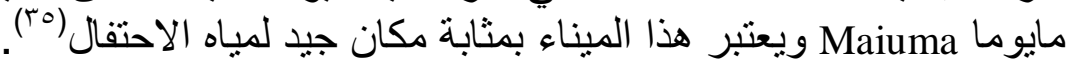

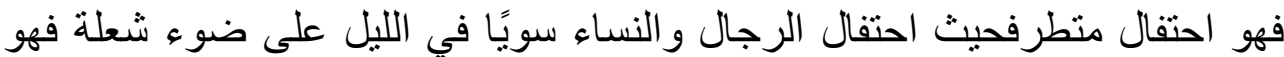

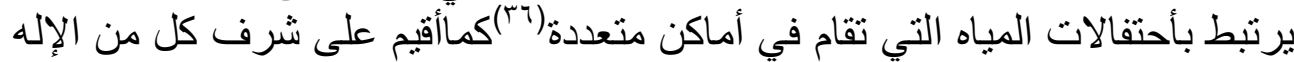

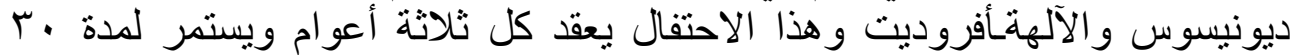

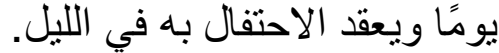
ولقد أصدر الإمبراطور كومودوس قرارًا الأي أعاد فيه الألعاب الأوليمبية بما

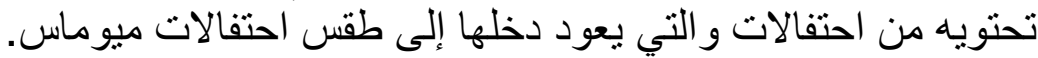

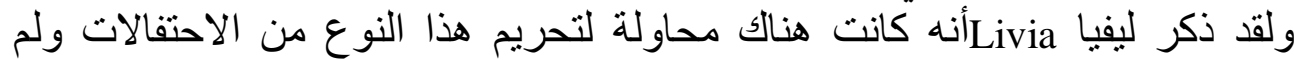

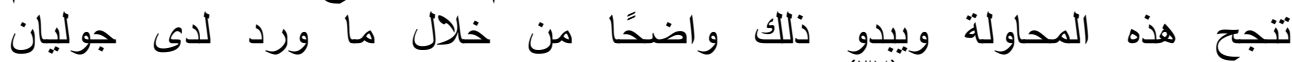

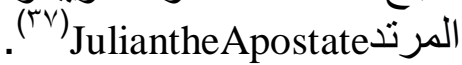

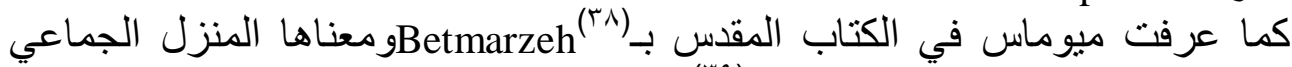

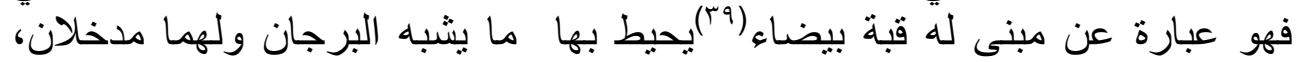

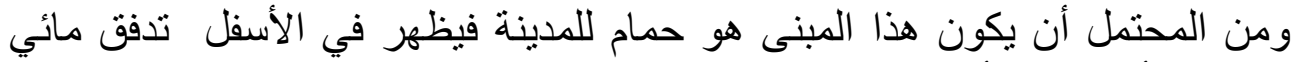

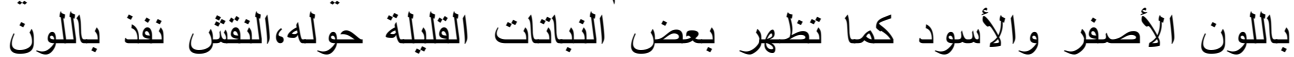
الأسود على خلفية بيضاء (صورة رقم 1 ( ).

(זr) (بأطلق عليها كذلك بيتومارسياس أي منزل لجماعة أو نادي.

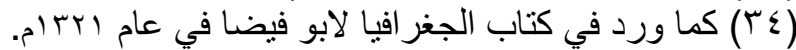

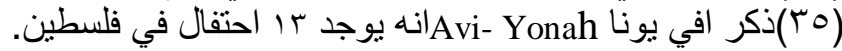

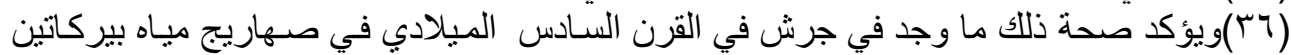
Birkatein

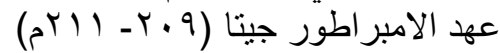
(37)http://www.jewishvirtuallibrary.org/jsource/judaica/ejud_0002_0013_0_13058.html

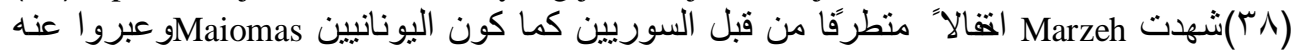

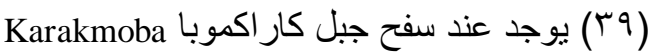


الشتهرت كحمام استشفائي(·)رفيهي يحيط به حدائق الرمان كما بتمتع بالمياه

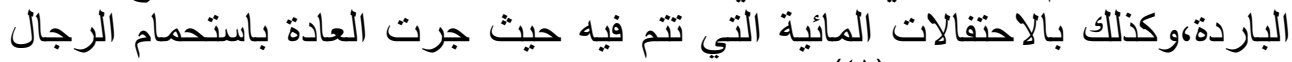

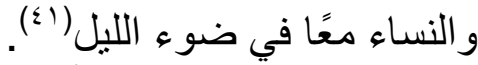
تم الكثفعن بعض البقابا الأثرية بواسطة E.Shenhav نيابة عن وزارة المابة المالية القومية

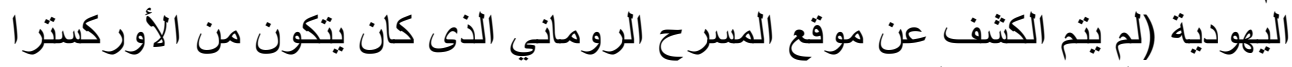
وصفوف المشاهدين و القباب).

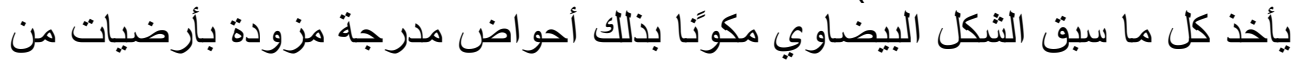

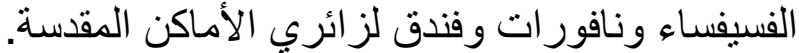

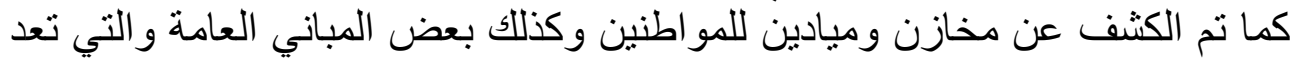

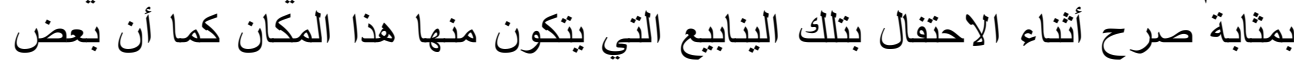

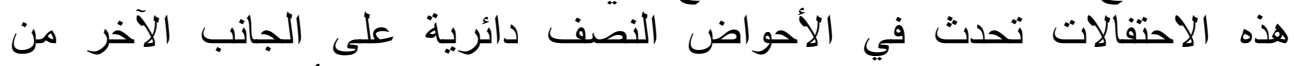

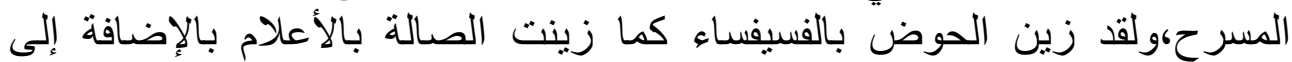

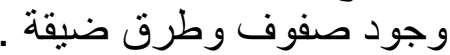

ويشير ذلك إلى اتجاهات مياه الألعاب و المناصب التي توصل إلى إليها اللاعبين كمايوجد

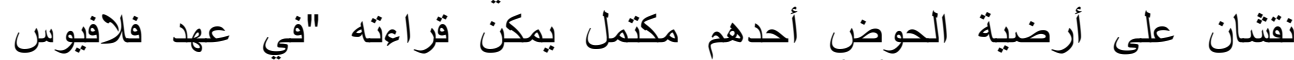

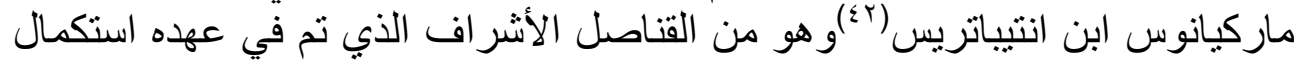

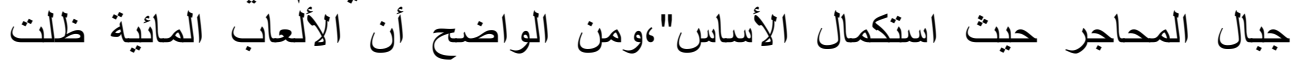
مستمرة في بداية الفترة البيزنطية.

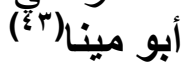

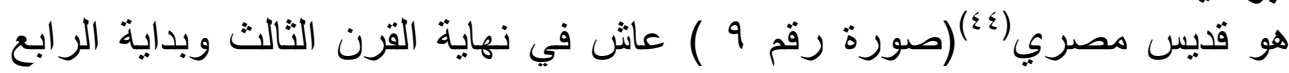

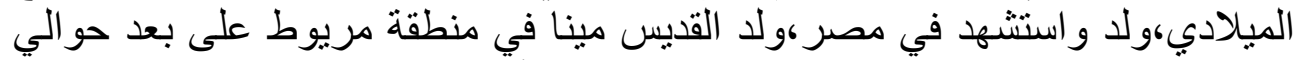

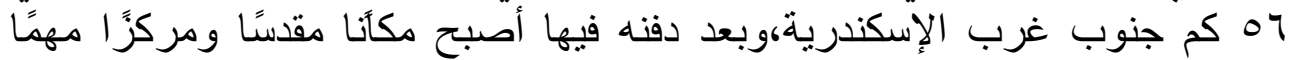

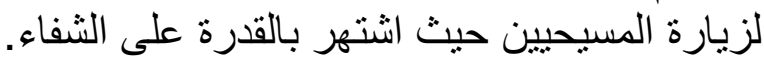

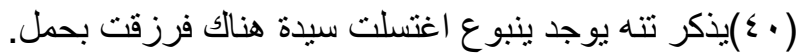

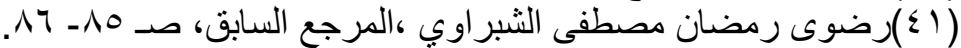

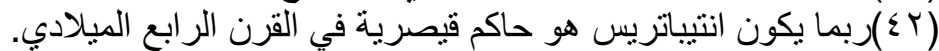

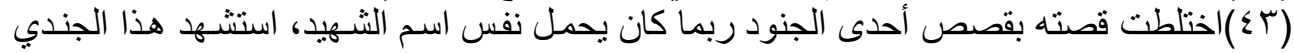

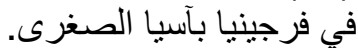

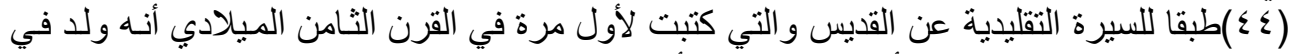

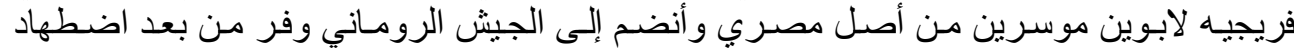

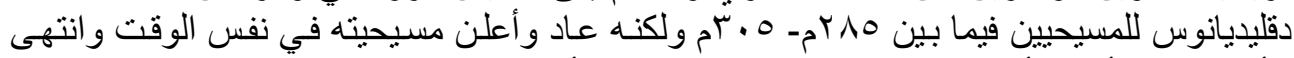

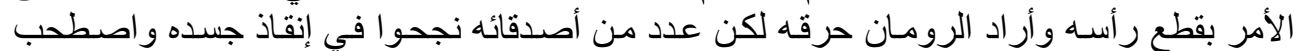

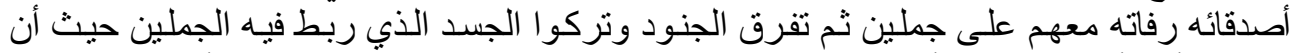

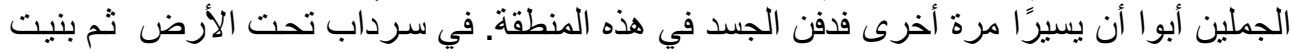
كنيسه فوق المقبرة. 
بعد استشهاده حدثت عدة معجزات(0؛)في هذه المنطقة حول قبر القديس والكنائس

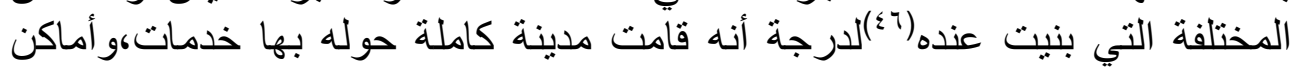

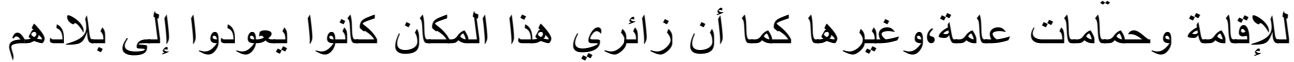

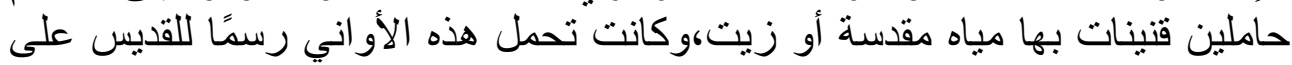

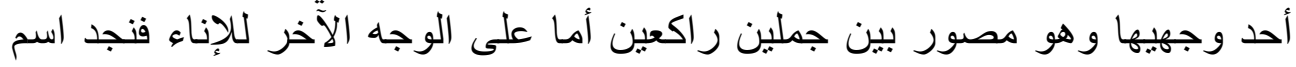

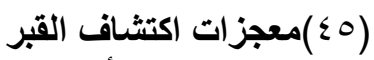

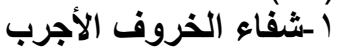

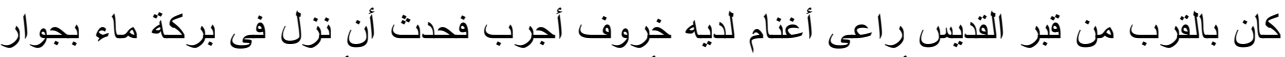

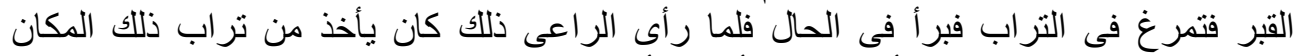

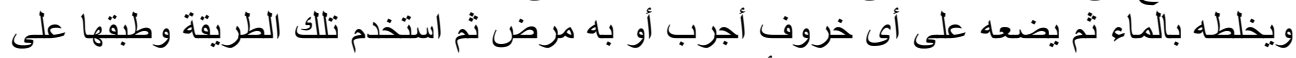

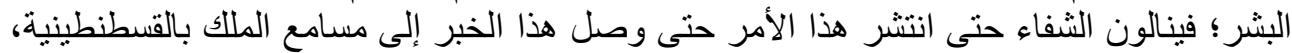

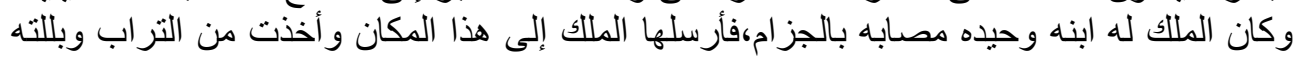

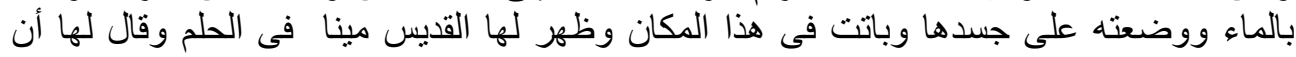

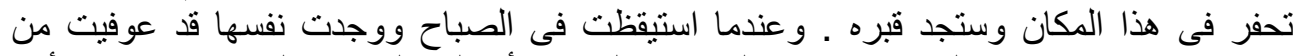

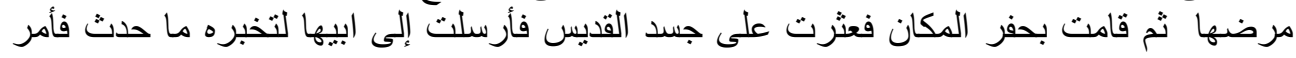
ببناء كنيسه فوق قبر القديس.

\section{سنكسار مخطوط محفوظ بكنيسة السيده العزراء مريم بالبتانون - منوفية}

سنكسار مخطوط محفوظ بكنيسة السيده العزراء مريم بالضهرية ـبحيرة

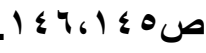

ك-شفاء الطقل الكسيح

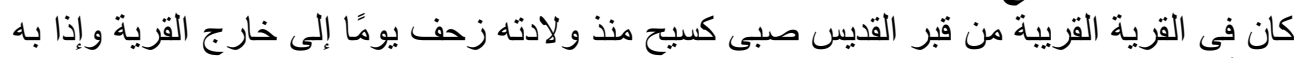

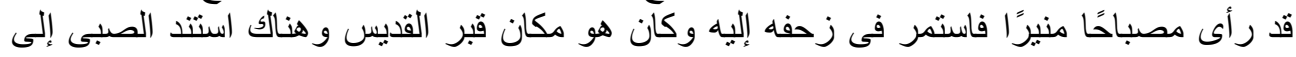

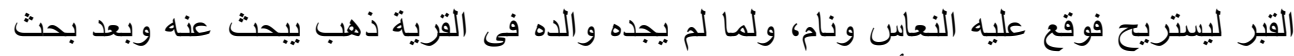

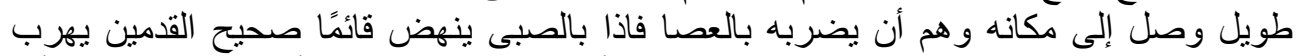

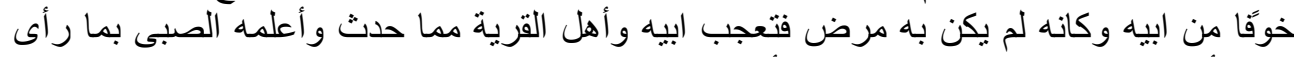

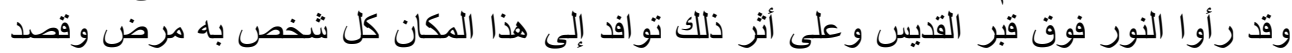

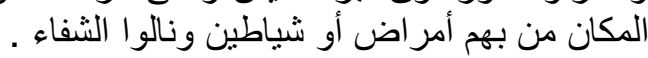

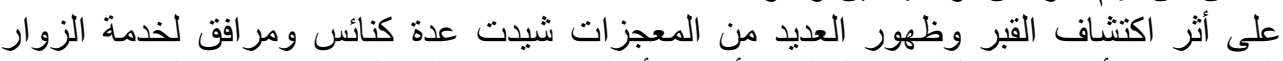

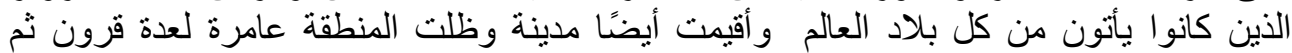

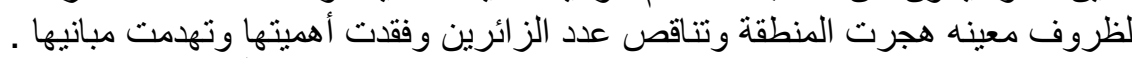

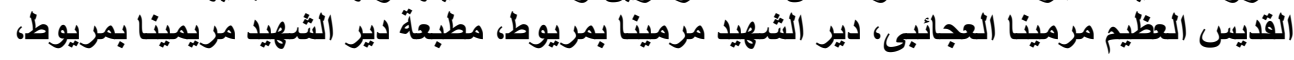

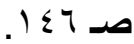

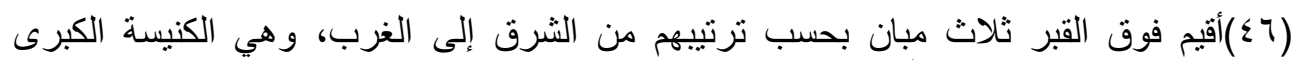

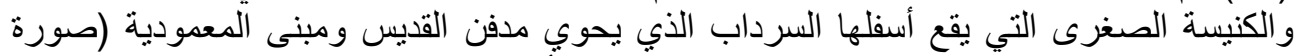
رقم • (1) وقد قام بالكثف على لهن هذه المباني العالم الألماني كاوفمان الذي تحدث عن الاتقان

Kaufmann-Die hielge der Wuste, 1924, P. 119 المعماري لزذه المباني. 
القديس مكتوبا عليها(صورة رقم 1) (1) اشتهرت هذه المنطقة بالكروم لذا سميت في

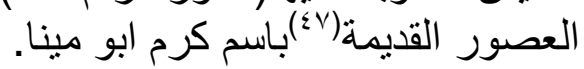

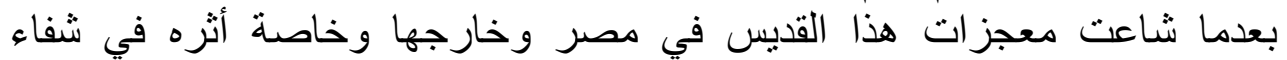

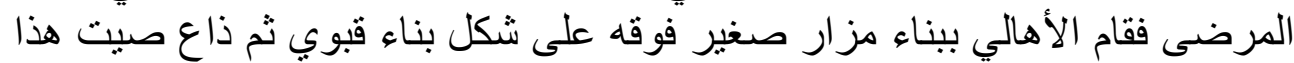

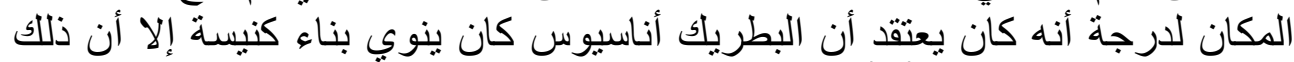

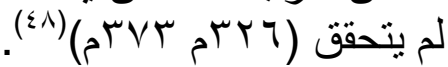
مزار القديس ابو مينا بنى للقديس في أواخر القرن الريسا ابع موضعًا صغيرًا للصداة فوق القبر يشبه القبة

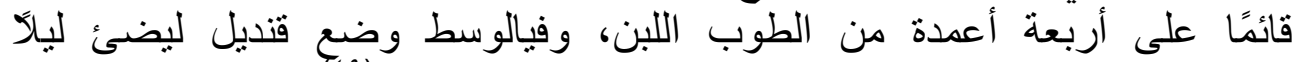

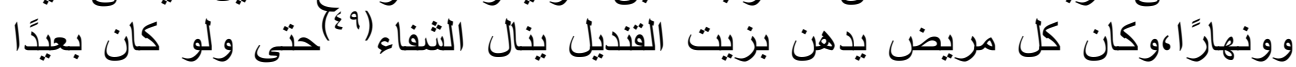
فتو افد الكثيرون يلتمسون الثنفاء مدا أدى إلى ضئ ضيق المكان.

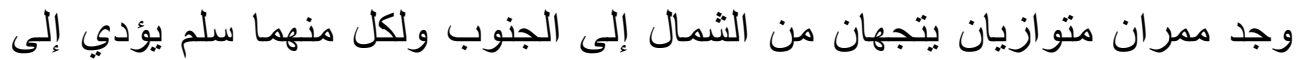

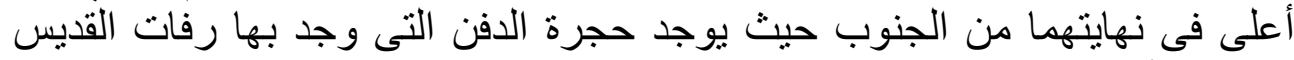

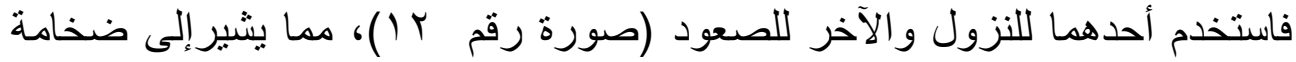

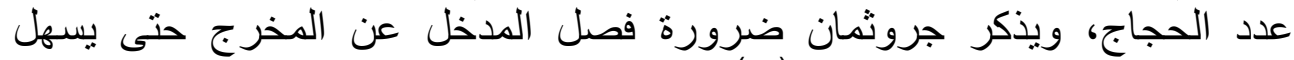

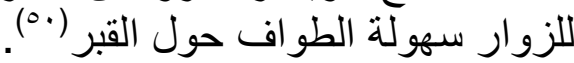

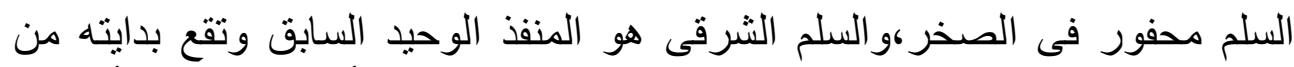

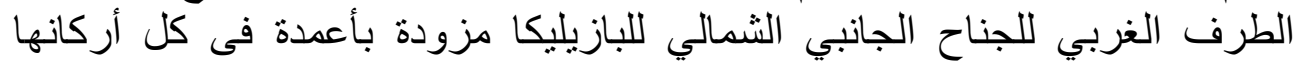

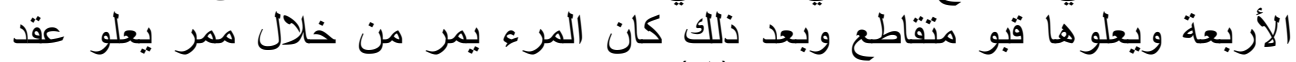

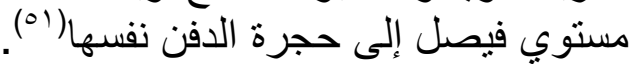

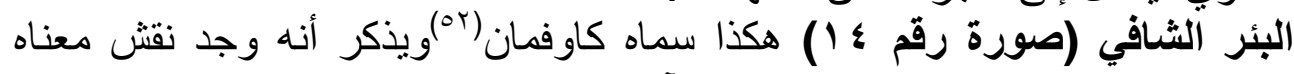

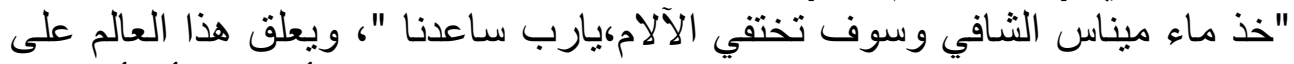

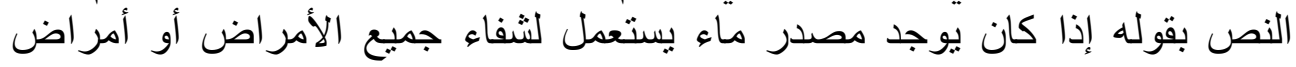

(§V) وصلت هذه المدينة إلى قمة أوجها في القرن الخامس ثم تدهورت مع ضعف الإدارة البيزنطية

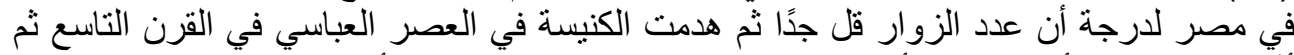

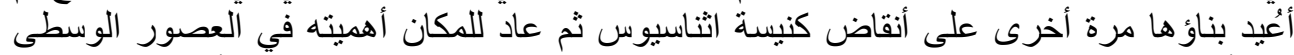

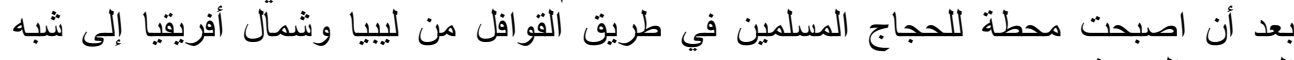

(48) Breccia, Alexandrea ad Aegyptum,p.130.

الجزيرة العربية.

(50)Coptic Encyclopedia, Vol. 1 p.24

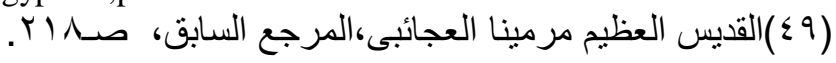

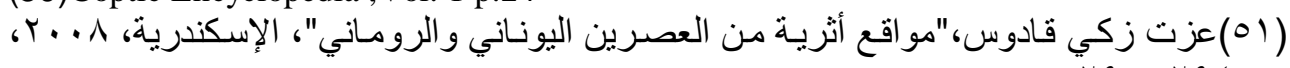
صـ

(52) K.M.Kaufmann ,Die Menasstadt und das Nationalheiligtum der Altchristlichen Aegypten, Leipzig, 1910. 


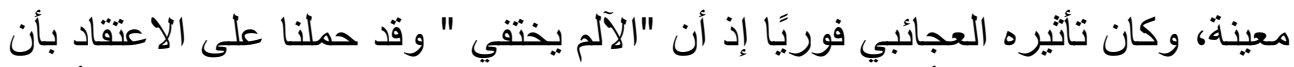

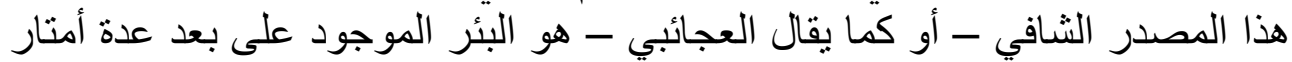

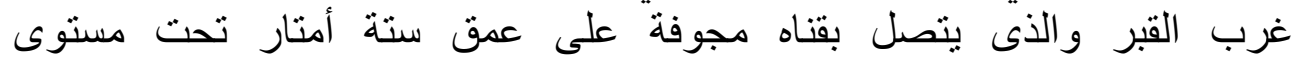

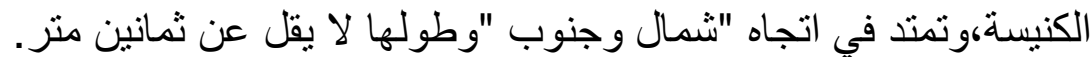

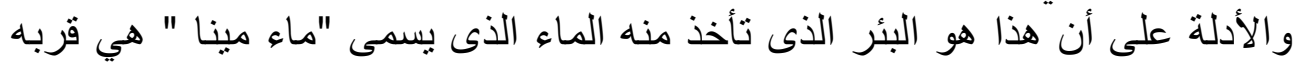

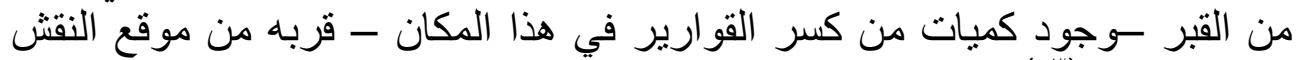
الأثري السابق (or). كنيسة الانزي المدفن

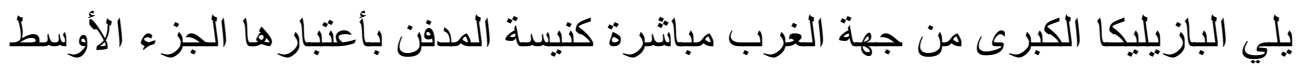

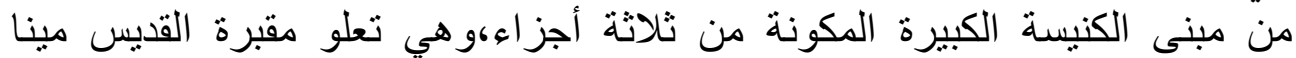

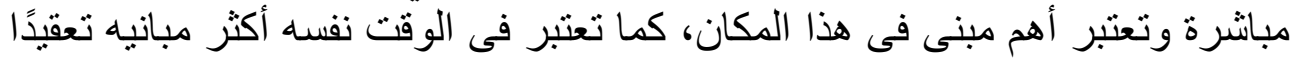

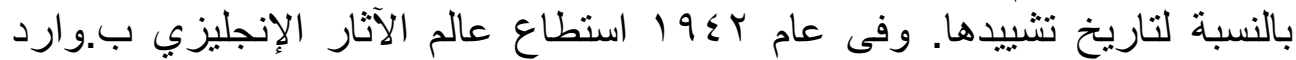

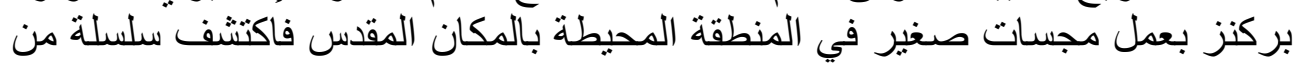

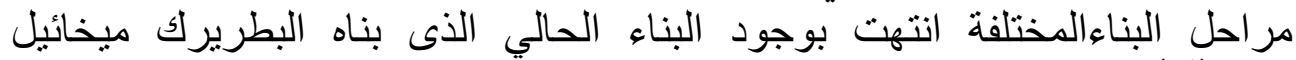

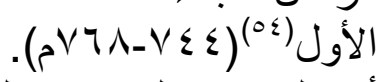

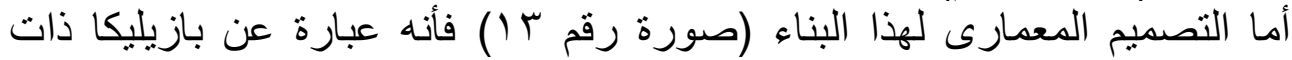

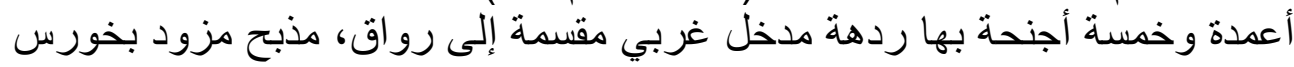

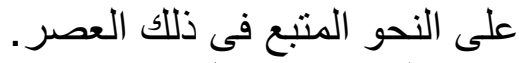
وكان الخورس بثنغل مكان ردهة المدخل الخاص بالبازيليكا القديمة واحتلت الحنة الحنية

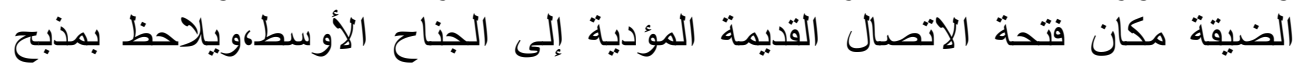

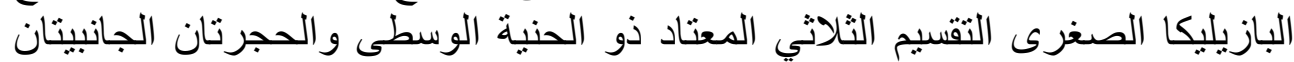

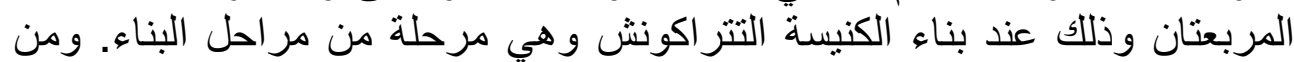

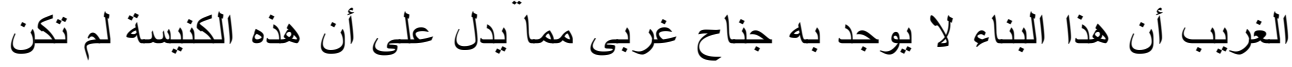
ذات شرفات علوية. يرجع المبنى إلى النصف الأول من القرن الخامس ويبدو أنه استخدم لفترة طويلة لأنه

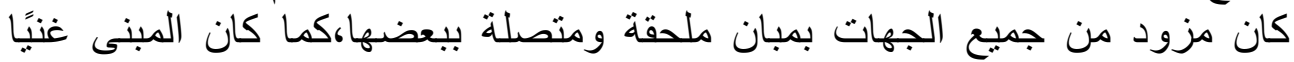

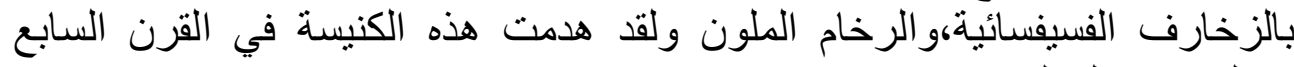
خلال الإحتلال الفارسي.

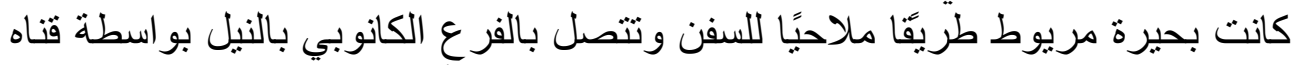

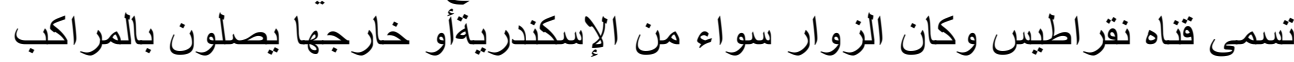

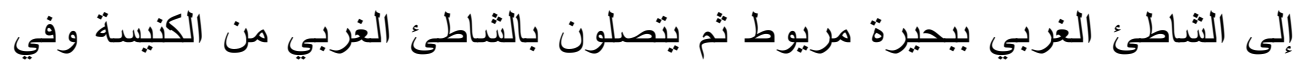

(53)Dictionary D'Archeologue Chretiene et de Liturgie Tome Onzieme, premiere partie, Paris, 1933, P.363,364.

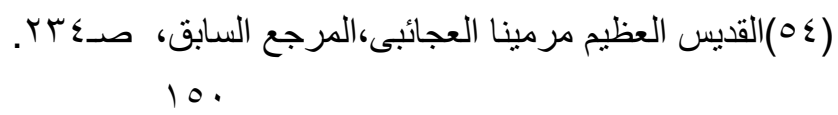




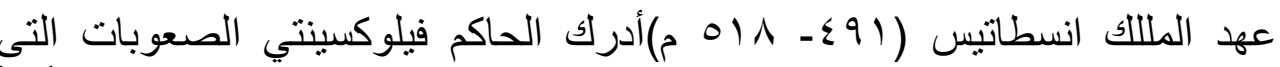
تواجه الزوار في الطريق الذي يخترق المنطقة الصحر اوية بالبحيرة والكئية الكنيسة فأنشأ

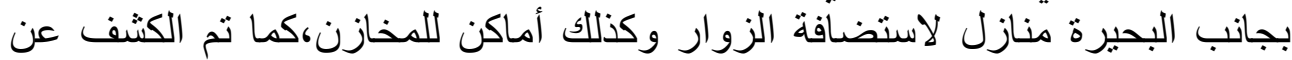

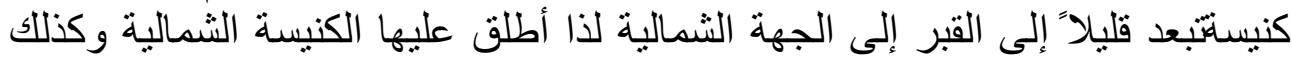

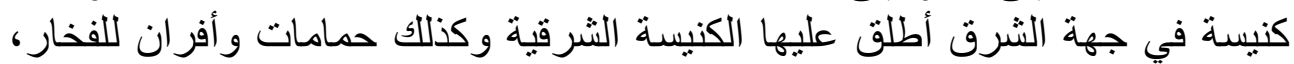

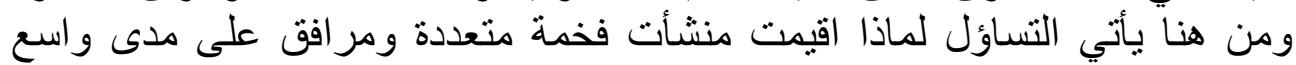

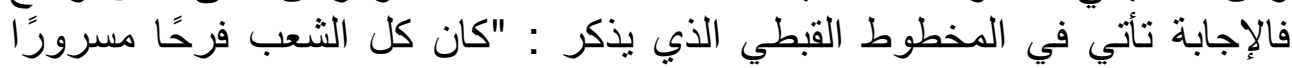

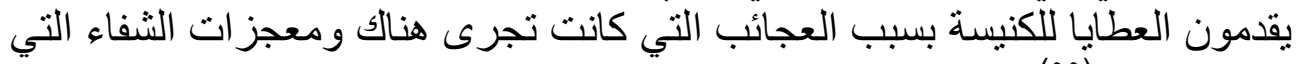
تتم بو اسطتهه"(00).

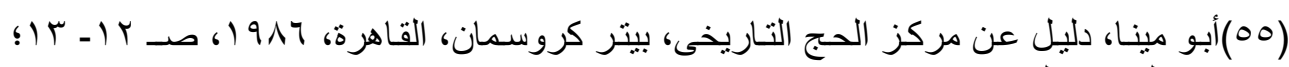
ماريمينا، المرجع السابق، صـ1/1) -ـ. 


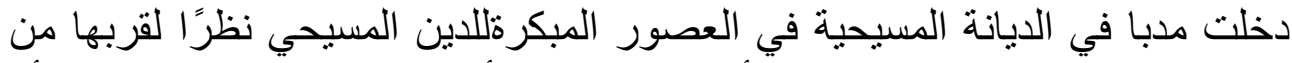

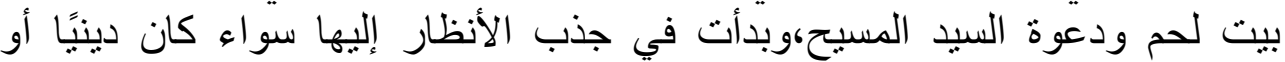

اقتصاديًا أو سياسيًا .

يعتبر عصر جستنيان هو أزهى عصور مدبا حيث ما عرف عن عن ولع جستنبان

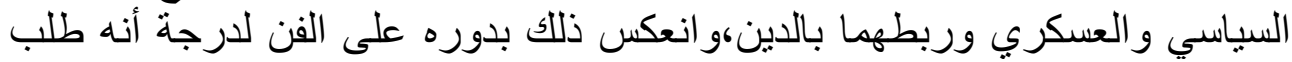

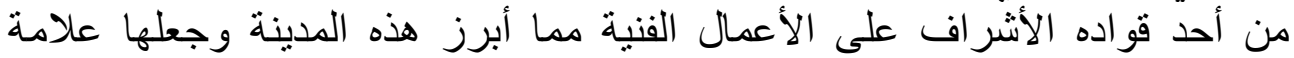

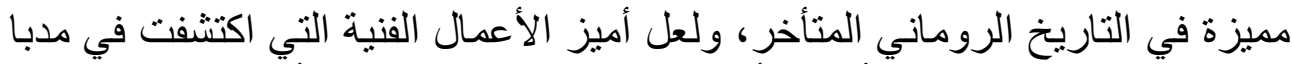

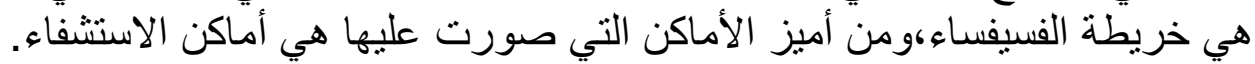

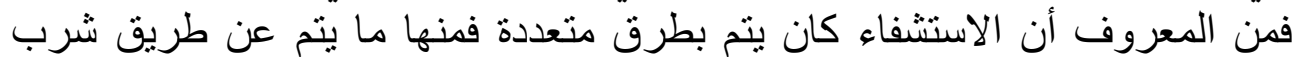

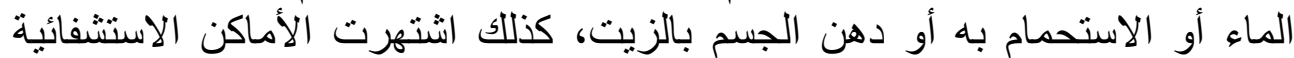

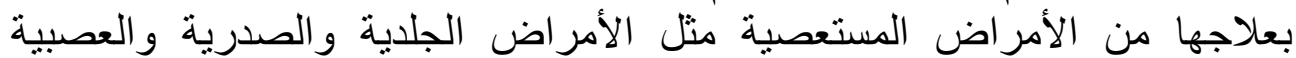

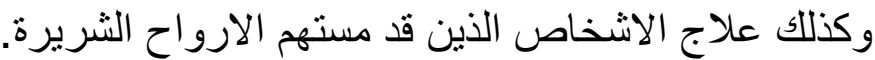

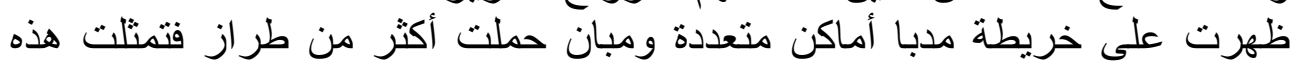

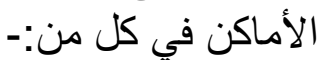
أماتوسوهو المعروف بتل فئل الحمام (صورة رقم ب)،مقام القديس اليشعأو عين

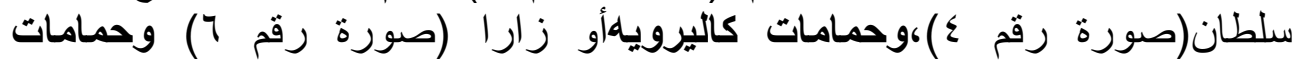

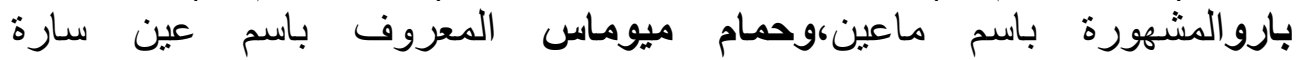

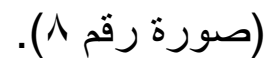
كانت تختلف كل طريقة للعلاج عن الأخرى فاستخدم العلاج بالاستحمام في اماتوس

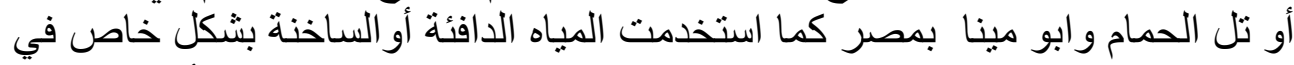

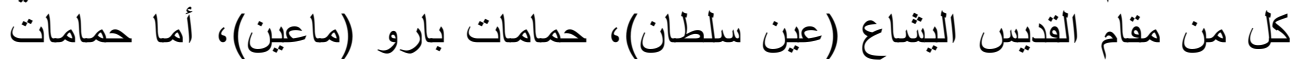

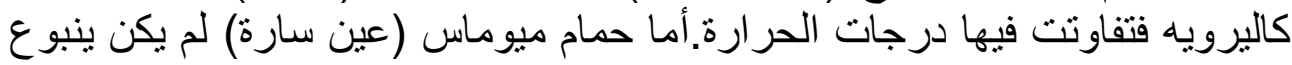

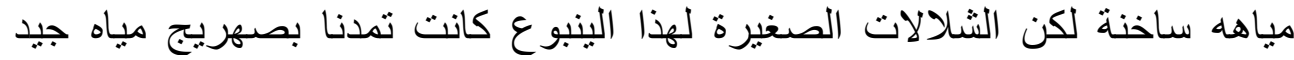
يمكن استخدامه في احتفال مايوس.

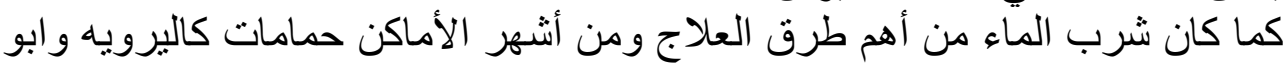

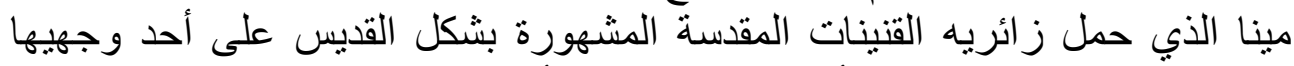
(صورة رقم 11 ) مملوءة أما بالماء المقد أو الزيه الزيت القنديل الموجود في قبر الفيل الشهيد.

استخدمت الطرز المعمارية المختلفة في بناء الاماكن الاستشفائية فتعددت ما بين

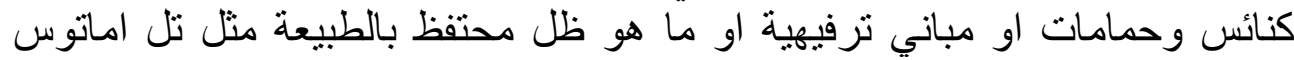
(تل الحمام) الذي اشتهر بموقعه الحصين ومياهه الوفيرة في العصر البيزنطي. 
استخدمت بعض الاماكن الاستئفائية في الكنائس مثل مقام القديس اليشع التي اخذت وحن

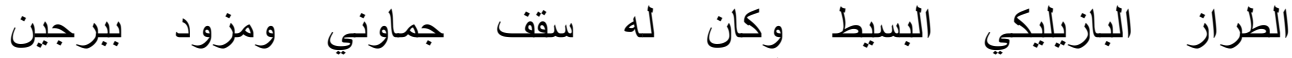

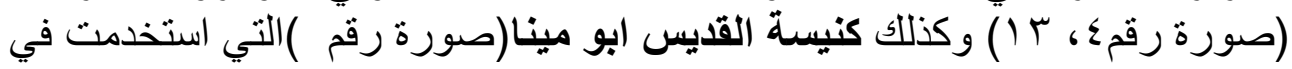

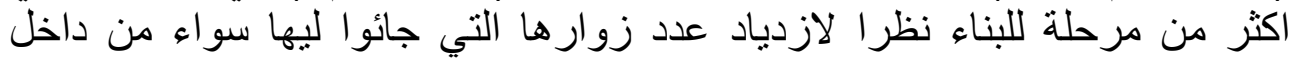

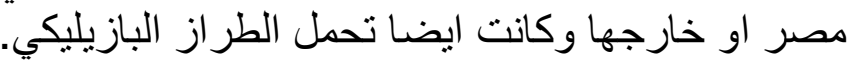

الحمامات

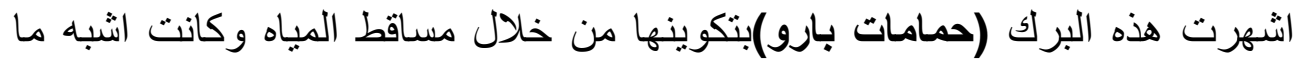

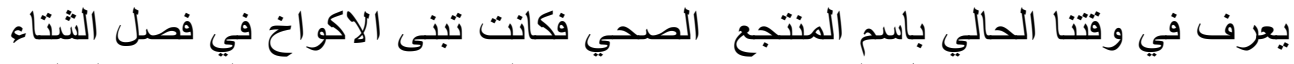

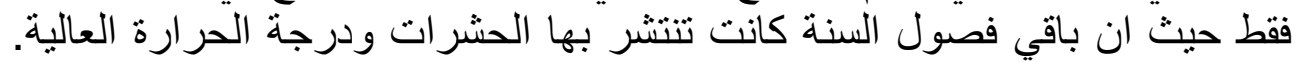
احو اض في

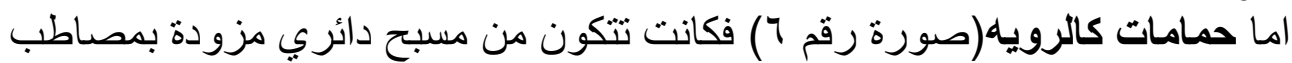

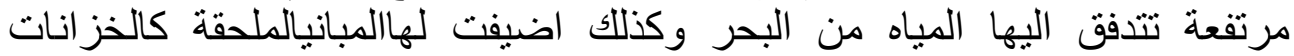
و النافور ات.

مباني الدائرية (الترفيهية)

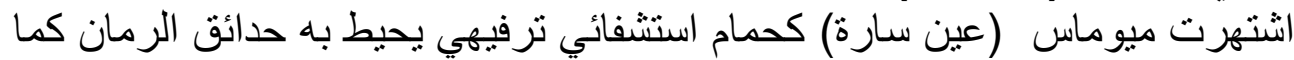

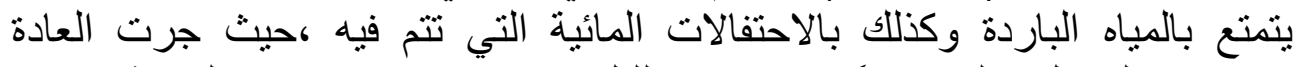

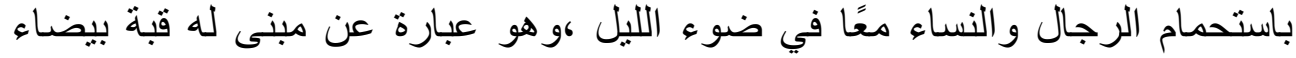

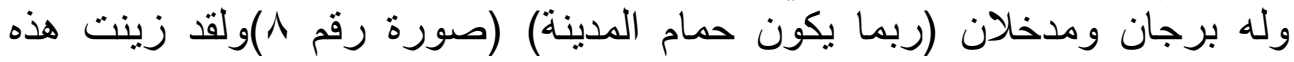
الاحو اض بالفسيفساء و الاعلان (ردمان. 

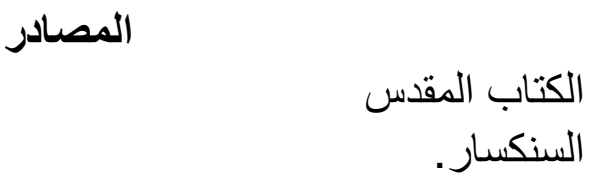

- Josephus, Jewish War, Book: I - 7, Trans. By: Thackeray, H. ST. J., LCL., 1981.

- Josephus, Jewish Antiquities, Book: 17, Trans. By: Marcus, Ralph, LCL, 1984.

- Pliny, Natural History, Book: 28, Trans. By: Jones, W.H.S, LCL, 2000.

- $\quad$ Pliny, Natural History, Book: 5, Trans. By: Jones, W.H.S, LCL, 1986.

- $\quad$ Eusebius, Onomasticon,Book: 44: 22; 112: 117,Trans. By: Oulton, J.E.L., LCL, 1994.

- $\quad$ Ptolemy, Geography,Book: 5, Trans By: Robbins, F.E., LCL, 1994.
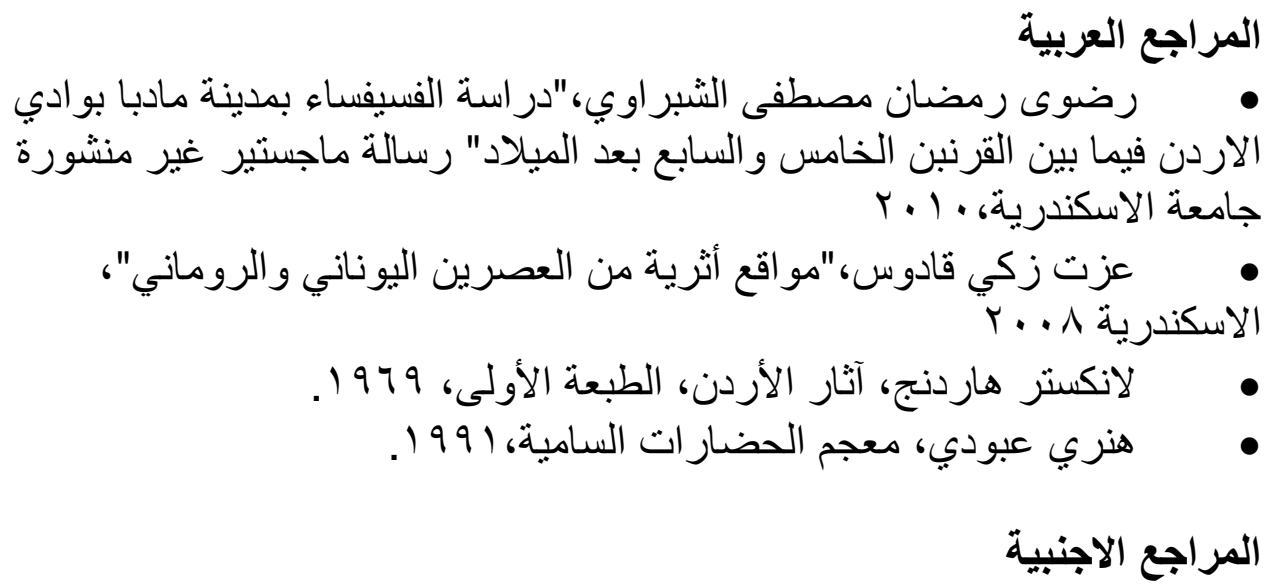

- $\quad$ Aupert, p., 1997, "Amathus during the first Iron Age", BASOR, vol,308.

- $\quad$ Breccia, Alexandrea ad Aegyptum,1932, Italy.

- Clamer,C., 1999,'The Hot Spring of Kallirrhoe and Baarou”,Michele Piccirillo,Eugenio Alliata(Edit.,), in :The Madaba Map Centenary 18971997:Traviling through the Byzantine Proceeding of Umayyed Period the International Conference Held in Amman 7-9 April 1997, Jerusalem.

- $\quad$ Donner ,H.,1984, “Transjordan and Egypt on the Mosaic Map of Madaba", ADAJ, Vol 28.

- Donner, H., 1963, "Kallirrhoe, das Sanatorium Herdes, des Groben, "ZDPV, Vol.79. 
- $\quad$ Graves, D.E.,Stripling, S.,2007., "Locating Tall el-Hammam on the Madaba Map", BRB, Vol7, No6* Tsafrir, Y., 1986, "The Maps used by Theodosius. On the Piligrim Maps of the Holy Land and Jerusalem in the Sixth Century C.E", DOP.

- $\quad$ Mathews, S., 1898, “In Elijah's Country”, BW,Vol.12, No.3. - $\quad$ Tsafrir, Y., 1986, “The Maps used by Theodosius. On the Piligrim Maps of the Holy Land and Jerusalem in the Sixth Century C.E", DOP.

- $\quad$ Weber, T., "Thermal Spring, Medical Supply and Healing Cults in Roman-Byzantine Jordan”, SHAJ, Vol.6.

المواقع الإلكثرونية

- $\quad$ http://st-takla.org/Full-Free-Coptic-Books/FreeCopticBooks-002Holy-Arabic-Bible-Dictionary/01_A/A_377.html

- http://www.jewishvirtuallibrary.org/jsource/judaica/ejud_0002_0013 _0_13058.html 
دراسات في آثار الوطن العربي 17

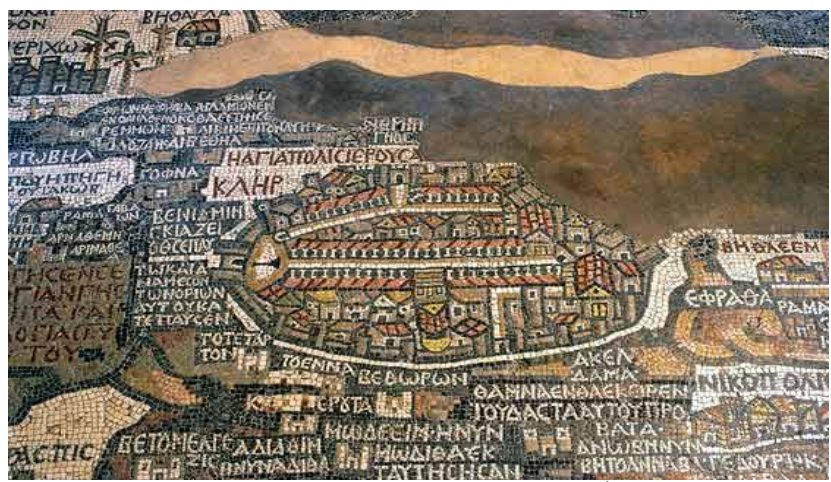

فسيفساء مدبا (صورة رقم 1)

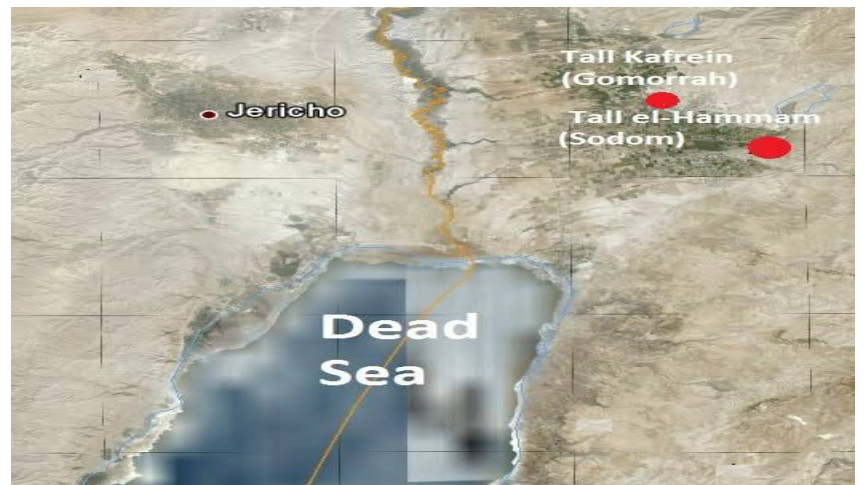

موقع تل الحمام (صورة رقم )

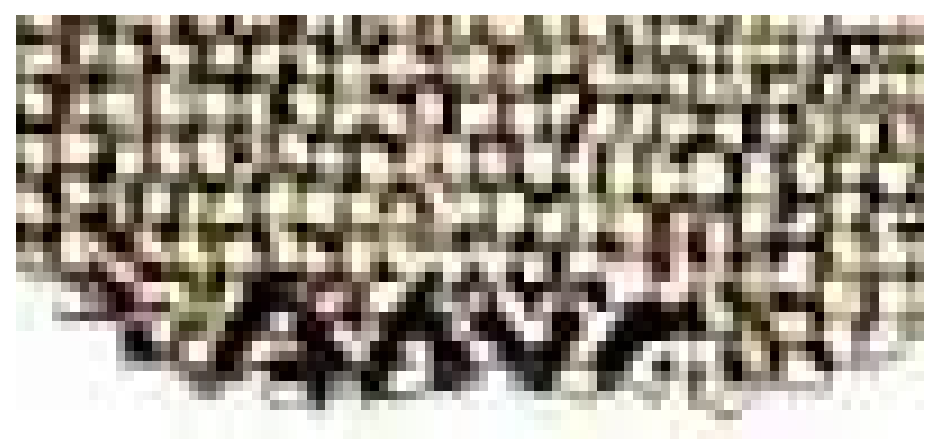

تل الحمام (صورة رقم ؟َ) 
دراسات في آثار الوطن العربي 17
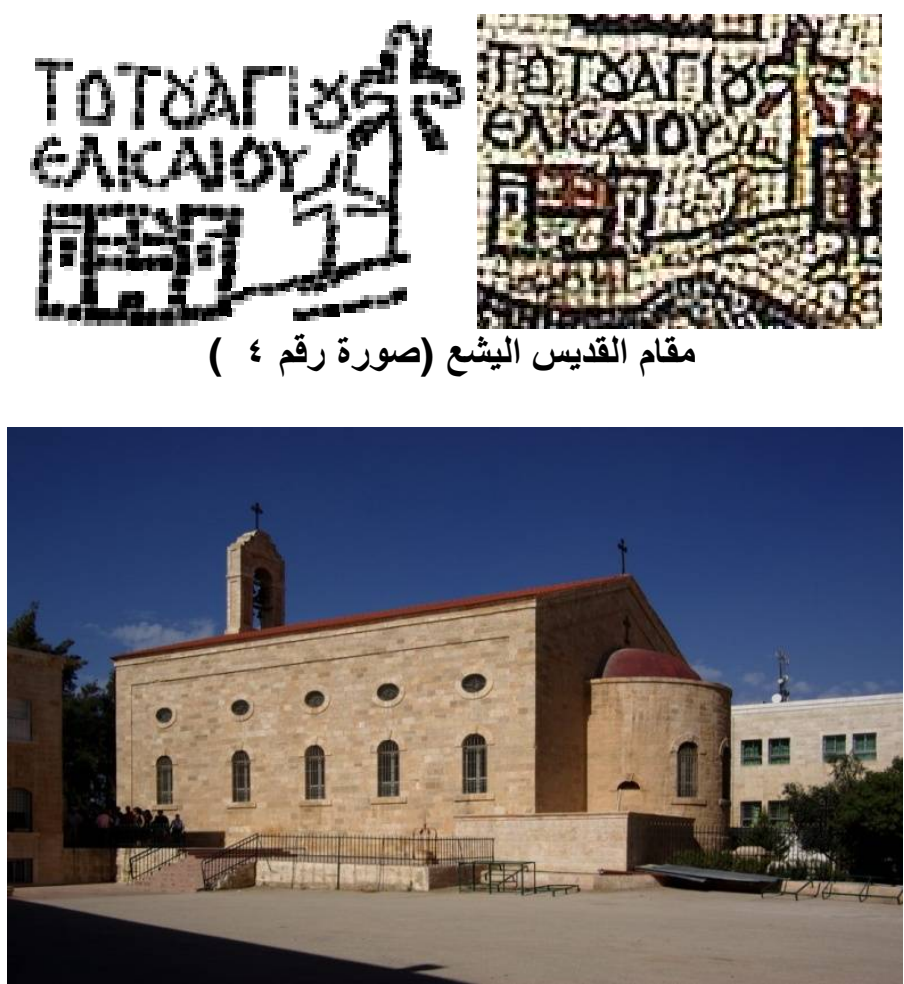

كنيسة القديس سانت جورج (صورة رقم •)

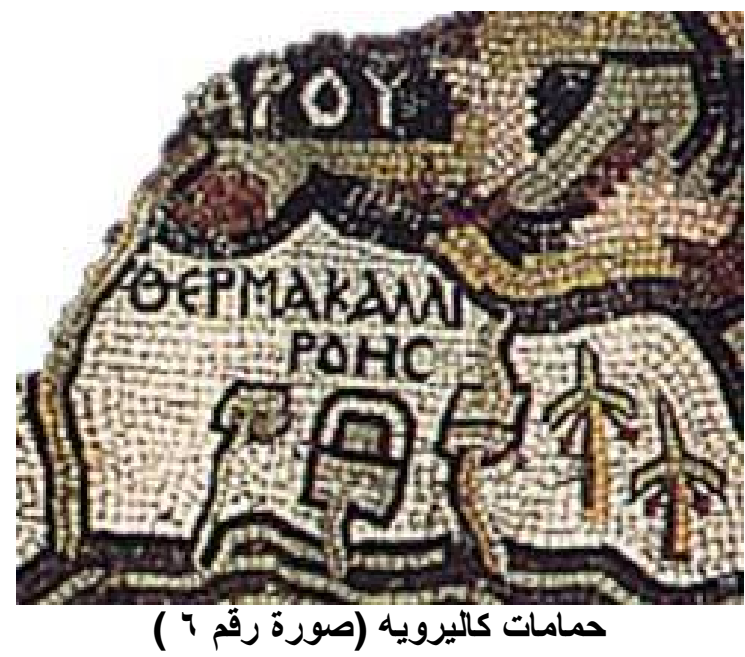


دراسات في آثار الوطن العربي 17

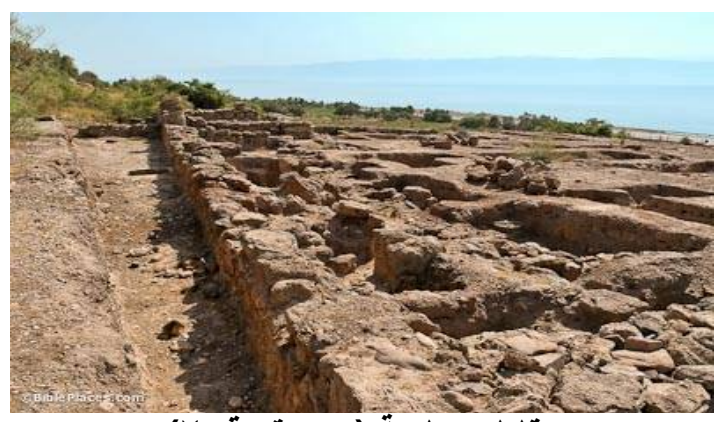

بقايا معمارية (صورة رقم V)

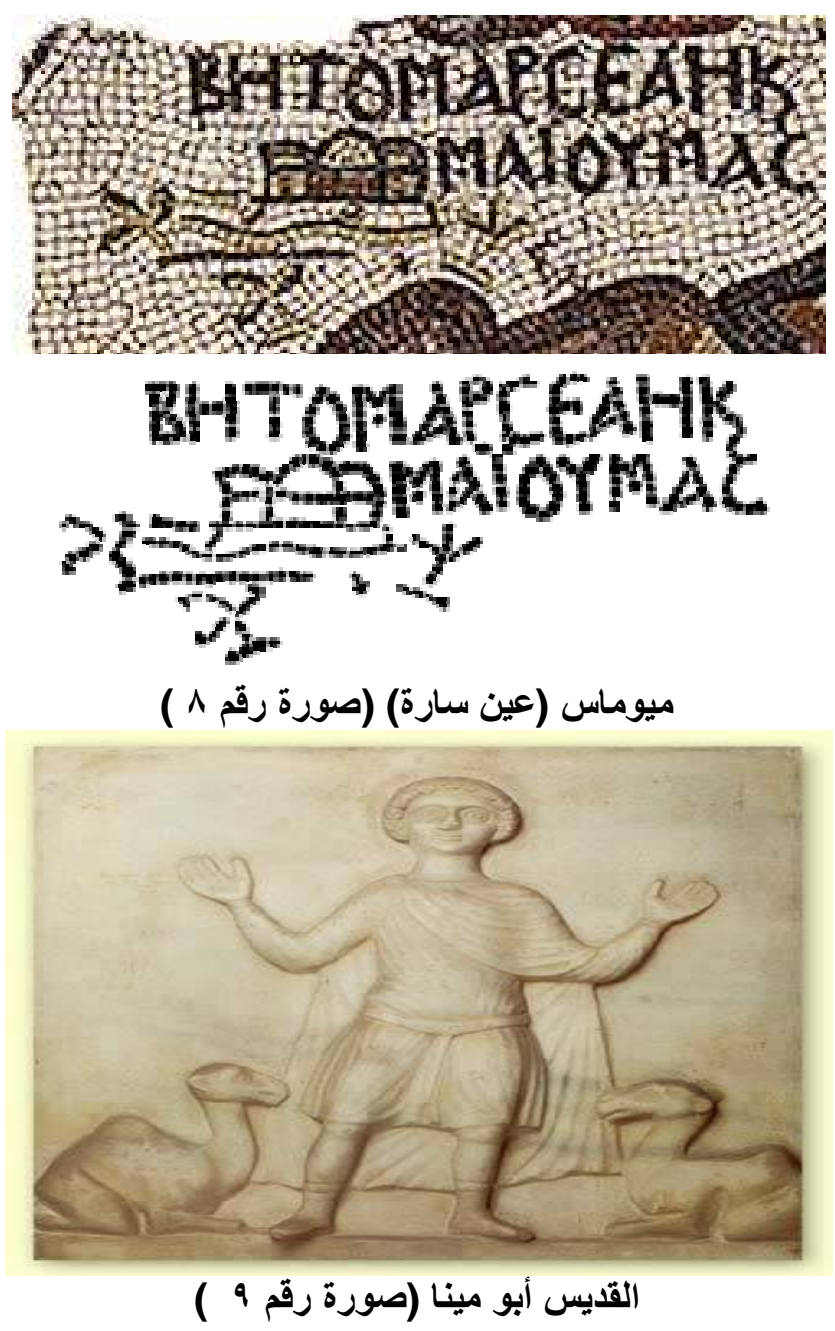



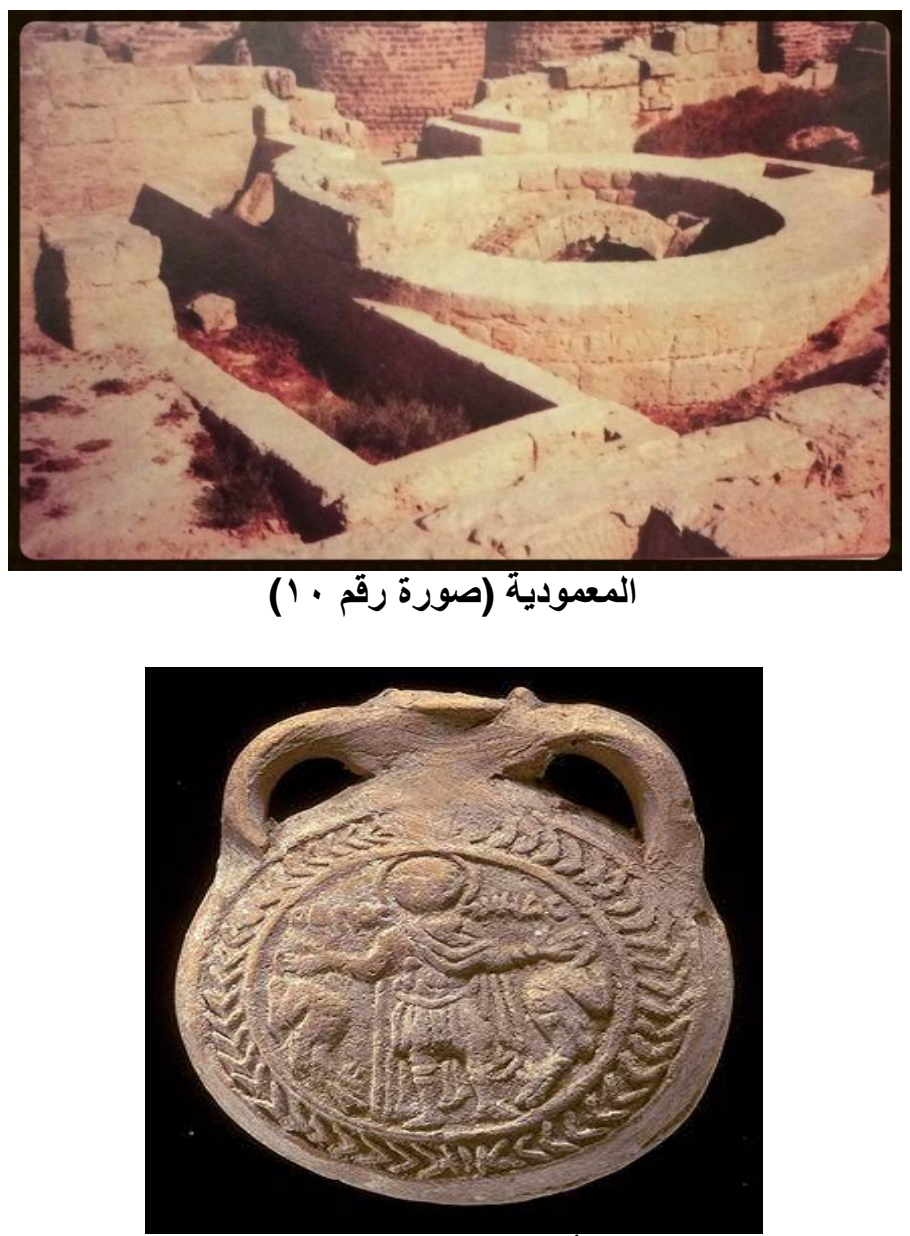

قتنينات أبو مينا (صورة رقم 1')

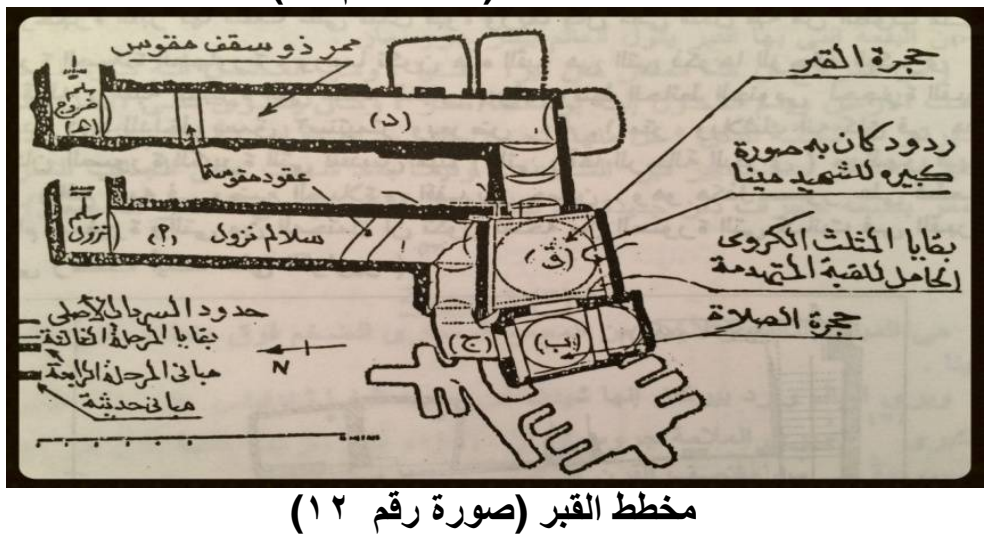


دراسات في آثار الوطن العربي 17
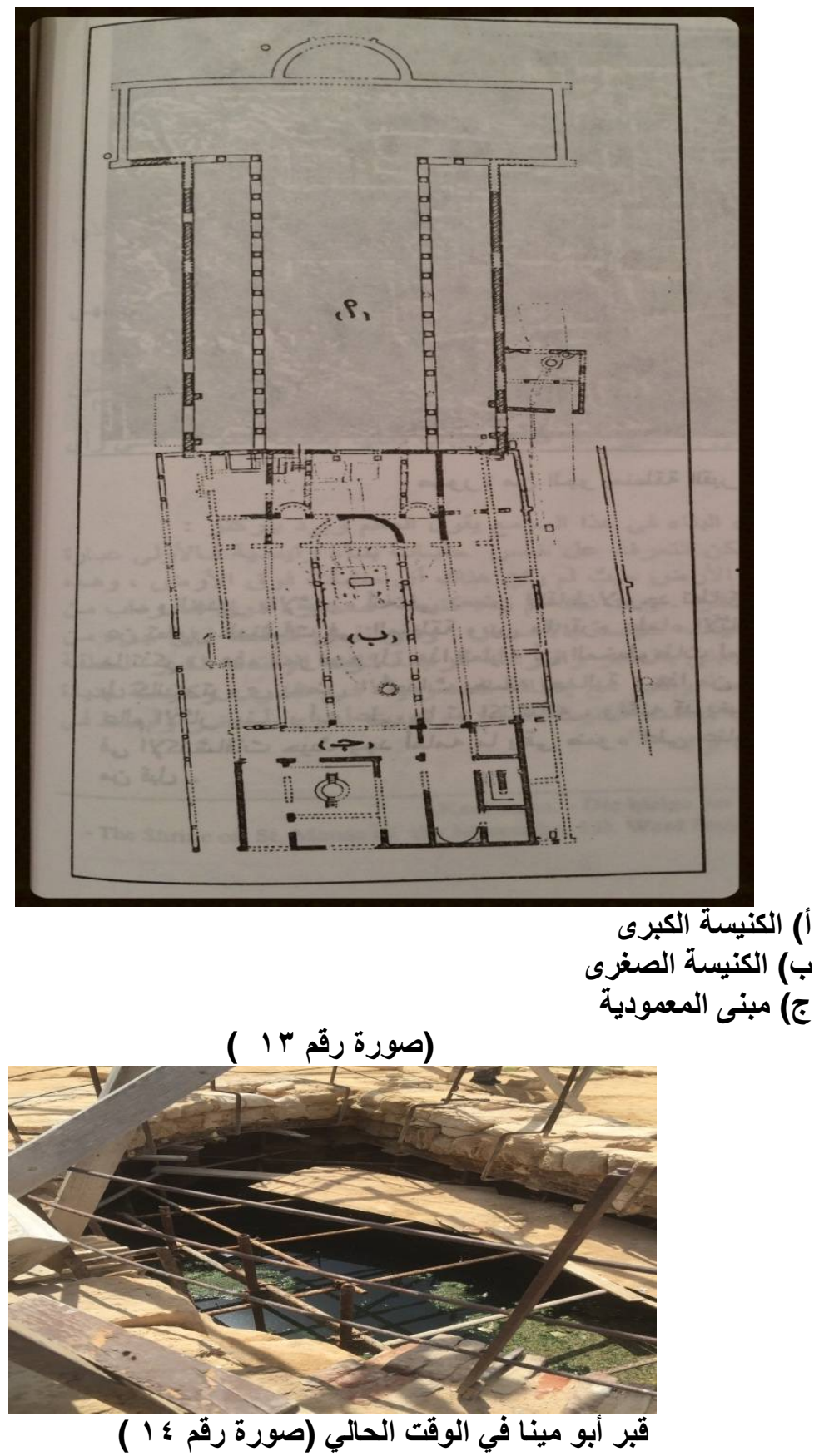